\title{
CAMA
}

Centre for Applied Macroeconomic Analysis

\section{The Natural Rate of Interest in a Nonlinear DSGE Model}

\section{CAMA Working Paper 38/2017 May 2017}

\section{Yasuo Hirose}

Faculty of Economics, Keio University and

Centre for Applied Macroeconomic Analysis, ANU

\section{Takeki Sunakawa}

Center for Social Systems Innovation, Kobe University

\begin{abstract}
This paper investigates how and to what extent nonlinearity, including the zero lower bound on the nominal interest rate, affects the estimates of the natural rate of interest in a dynamic stochastic general equilibrium model with sticky prices and wages. We find that the estimated natural rate of interest in a nonlinear model is substantially different from that in its linear counterpart because of a contractionary effect of the zero lower bound, and that other nonlinearities such as price and wage dispersion, from which a linear model abstracts, play a minor role in identifying the natural rate.
\end{abstract}




\section{Keywords}

Natural rate of interest, Nonlinearity, Zero lower bound, Particle filter

\section{JEL Classification}

C32, E31, E43, E52

\section{Address for correspondence:}

(E) cama.admin@anu.edu.au

ISSN 2206-0332

The Centre for Applied Macroeconomic Analysis in the Crawford School of Public Policy has been established to build strong links between professional macroeconomists. It provides a forum for quality macroeconomic research and discussion of policy issues between academia, government and the private sector.

The Crawford School of Public Policy is the Australian National University's public policy school, serving and influencing Australia, Asia and the Pacific through advanced policy research, graduate and executive education, and policy impact. 


\title{
The Natural Rate of Interest in a Nonlinear DSGE Model*
}

\author{
Yasuo Hirose ${ }^{\dagger} \quad$ Takeki Sunakawa ${ }^{\ddagger}$
}

May 2017

\begin{abstract}
This paper investigates how and to what extent nonlinearity, including the zero lower bound on the nominal interest rate, affects the estimates of the natural rate of interest in a dynamic stochastic general equilibrium model with sticky prices and wages. We find that the estimated natural rate of interest in a nonlinear model is substantially different from that in its linear counterpart because of a contractionary effect of the zero lower bound, and that other nonlinearities such as price and wage dispersion, from which a linear model abstracts, play a minor role in identifying the natural rate.
\end{abstract}

Keywords: Natural rate of interest, Nonlinearity, Zero lower bound, Particle filter JEL Classification: C32, E31, E43, E52

\footnotetext{
${ }^{*}$ The authors would like to thank Guido Ascari, Florin Bilbiie, Matthieu Darracq Pariès, Martin Ellison, Jesús Fernández-Villaverde, Andrea Ferrero, Masashige Hamano, Michel Julliard, Munechika Katayama, Takushi Kurozumi, Taisuke Nakata, Patrick Pintus, Sebastian Schmidt, Mototsugu Shintani, Georg Strasser, Tomohiro Sugo, Hitoshi Tsujiyama, Takayuki Tsuruga, Kozo Ueda, Francesco Zanetti, and seminar and conference participants at the European Central Bank, Goethe University Frankfurt, Sophia University, the University of Oxford, the University of Tokyo, and the International Workshop on Monetary Policy when Heterogeneity Matters, for their insightful comments and discussions. Hirose acknowledges the support from a JSPS KAKENHI Grant-in-Aid for Young Scientists (B), Grant Number 26780124. Sunakawa acknowledges the support from Zengin Foundation for Studies on Economics and Finance.

${ }^{\dagger}$ Faculty of Economics, Keio University and Centre for Applied Macroeconomic Analysis, Australian National University. E-mail: yhirose@econ.keio.ac.jp

${ }^{\ddagger}$ Center for Social Systems Innovation, Kobe University. E-mail: takeki.sunakawa@gmail.com
} 


\section{Introduction}

The natural rate of interest - the equilibrium real interest rate that yields price stability (Wicksell, 1898) - has been a key concept for monetary policy analysis. In particular, a modern New Keynesian framework relates the concept of the natural rate to intertemporally optimizing agents and makes it relevant for social welfare (Woodford, 2003; Galí, 2008). The level of the natural interest rate in this framework is a useful indicator for policymakers because it is a benchmark as to whether policy is too tight or too loose from a welfare perspective. ${ }^{1}$ However, the natural rate is unobservable and must be estimated. Whereas the literature has developed various empirical methods to infer the natural rate of interest, an increasing number of researchers have estimated the natural rate measures based on New Keynesian dynamic stochastic general equilibrium (DSGE) models. ${ }^{2}$ Examples for the U.S. economy include Andrés, López-Salido, and Nelson (2009), Barsky, Justiniano, and Melosi (2014), Cúrdia (2015), Cúrdia, Ferrero, Ng, and Tambalotti (2015), Del Negro, Giannone, Giannoni, and Tambalotti (2017), Edge, Kiley, and Laforte (2008), Justiniano and Primiceri (2010), and Neiss and Nelson (2003).

This paper estimates the natural rate of interest in the U.S. using a nonlinear New Keynesian DSGE model with a zero lower bound (ZLB) constraint on the nominal interest rate and examines how and to what extent nonlinearity affects the estimates of the natural rate and its driving forces. Whereas the previous studies estimate the DSGE-based natural interest rate only in a linear setting that abstracts from the ZLB, this paper is the first to estimate the natural rate in a fully nonlinear and stochastic setting that incorporates the ZLB. ${ }^{3}$ Fernández-Villaverde and Rubio-Ramírez (2005) and Fernández-Villaverde, Rubio-Ramírez, and Santos (2006) demonstrate that the level of likelihood and parameter estimates based on a linearized model can be significantly different from those

\footnotetext{
${ }^{1}$ Closing the gap between the actual real interest rate and the natural rate is not necessarily optimal in the economy where "divine coincidence" (Blanchard and Galí, 2007) does not hold. However, Barsky, Justiniano, and Melosi (2014) demonstrate that, even in such a circumstance, the Federal Reserve would be able to stabilize both inflation and the welfare-relevant output gap to a considerable degree by tracking the natural rate using an estimated New Keynesian model.

${ }^{2}$ Another strand of the literature estimates the long-run natural interest rate based on semi-structural or reducedform models. See, for instance, Holston, Laubach, and Williams (2016), Johannsen and Mertens (2016), Kiley (2015), Laubach and Williams (2003, 2016), Lubik and Matthes (2015), Pescatori and Turunen (2015), and Williams (2015). Based on a DSGE model, Del Negro, Giannone, Giannoni, and Tambalotti (2017) present the estimates of the 20and 30-year forward natural rates, which are comparable to the long-run natural rate.

${ }^{3}$ A contemporaneous paper by Iiboshi, Shintani, and Ueda (2017), which evolved independently from our work, estimates a nonlinear New Keynesian model for Japan and extracts a sequence of the natural rate.
} 
based on the original nonlinear model, and the same may be true for the estimation of unobservable state variables, including the natural rate. Moreover, the recent experience of the Great Recession and the extremely low interest rate period that followed has led researchers to conduct empirical analyses based on nonlinear DSGE models in order to take the ZLB into consideration. For instance, Gust, Herbst, López-Salido, and Smith (2017) incorporate the ZLB into a medium-scale DSGE model similar to those developed by Christiano, Eichenbaum, and Evans (2005) and Smets and Wouters (2007), and estimate the model in a nonlinear setting using U.S. macroeconomic time series. Richter and Throckmorton (2016a, 2016b) estimate a nonlinear version of a prototypical New Keynesian model with the ZLB for the U.S. economy, and Iiboshi, Shintani, and Ueda (2017) estimate a similar model for the Japanese economy. Aruoba, Cuba-Borda, and Schorfheide (2017) consider Markov switching between the targeted-inflation and deflation steady states in a New Keynesian framework with the ZLB and estimate the probabilities of the U.S. and Japan having been in either the targeted-inflation or deflation regime in a nonlinear setting. The present paper contributes to these strands of the literature, focusing on the estimation of the natural rate.

In estimating the natural rate of interest, we follow the two-step approach in Aruoba, CubaBorda, and Schorfheide (2017). First, to parameterize the model, we estimate a linearized version of the model using U.S. data prior to the date when the nominal interest rate was bounded at zero. Hirose and Sunakawa (2015) demonstrate that a linearized DSGE model gives rise to biased estimates of parameters if the ZLB existing in an economy is omitted in estimation but that neglecting the other nonlinearities does not lead to biased estimates for a sample period during which the ZLB is not binding. Thus, this approach enables us not only to avoid a computational burden that would increase exponentially in the estimation of a fully nonlinear model, but also to obtain reliable estimates of parameters.

Next, given the estimated parameters, we solve the model in a fully nonlinear and stochastic setting with the ZLB and apply a nonlinear filter for a full sample to extract the sequence of the natural interest rate. The literature (e.g., Boneva, Braun, and Waki, 2016; Fernández-Villaverde, Gordon, Guerrón-Quintana, and Rubio-Ramírez, 2015; Gavin, Keen, Richter, and Throckmorton, 2015; Gust, Herbst, López-Salido, and Smith, 2017; Nakata, 2016a, 2016b; and Ngo, 2014) has emphasized the importance of considering nonlinearity in assessing the quantitative implications of New Keynesian models that include the ZLB. The natural rate estimated in the present paper takes account of this important feature. Moreover, our analysis is based on an empirically richer DSGE model than the prototypical New Keynesian model. The model features habit persistence in consumption preferences, price and wage stickiness, backward-looking components in price and 
wage settings, and monetary policy smoothing. Because of the high dimensionality of the state variables, it is computationally challenging to solve such a richer DSGE model in a fully nonlinear setting. To overcome this issue, we employ a projection method that adopts a very efficient Smolyak algorithm developed by Judd, Maliar, Maliar, and Valero (2014). Their solution method is very accurate, albeit with the reduced number of grid points.

The main results are summarized as follows. Comparing the estimated natural interest rate based on the nonlinear model with the rate based on the linear counterpart, we find that the former is higher than the latter to a substantial degree, particularly in the periods when the nominal interest rate is close to or bounded at zero. This difference is ascribed to a contractionary effect arising from the ZLB, which is considered only in the nonlinear model. Although such a contractionary effect lowers expected output and inflation, actual output and inflation are pegged to the corresponding observables in the filtering process. Then, positive shocks to aggregate demand must be identified as being larger in order to satisfy the optimality conditions of households and firms. As a consequence, the estimated natural rate increases in the nonlinear setting. Although other nonlinearities, including price and wage dispersion, potentially affect the identification of shocks and the estimates of the natural rate, we demonstrate that their effects are relatively minor. This point is confirmed by estimating the natural rate based on a quasi-linear model in which the ZLB constraint is imposed but all of the equilibrium conditions are linearized, and comparing it with the one based on the baseline nonlinear model. We find that these two estimates are very similar.

The remainder of the paper proceeds as follows. Section 2 describes the model used in our analysis and a strategy for estimating the natural rate of interest. Section 3 presents our results. Section 4 provides the conclusion.

\section{The Model and the Estimation Strategy}

This section begins by describing the model used in our analysis. In the model economy, there are households, perfectly competitive final-good firms, monopolistically competitive intermediate-good firms, and a central bank. To ensure a better fit to the macroeconomic time series, the model features habit persistence in consumption preferences, price and wage stickiness, backward-looking components in price and wage settings, and monetary policy smoothing. In the model, the natural rate of interest is defined as the real interest rate that would prevail if prices and wages were fully flexible without any markup shocks. 
To obtain the estimates of the natural interest rate, we follow the two-step approach in Aruoba, Cuba-Borda, and Schorfheide (2017). First, we estimate a linearized version of the model using U.S. data before the period of the global financial crisis and the virtually zero nominal interest rate. Next, given the estimated parameters, we solve the model in a fully nonlinear and stochastic setting with the ZLB constraint on the nominal interest rate and apply a nonlinear filter to extract the sequence of the natural rate.

\subsection{The model}

\subsubsection{Households}

Each household $h \in[0,1]$ consumes final goods $C_{h, t}$, supplies labor $l_{h, t}=\int_{0}^{1} l_{f, h, t} d f$ to intermediategood firms $f \in[0,1]$, and purchases one-period riskless bonds $B_{h, t}$ so as to maximize the following utility function

$$
\mathbb{E}_{0} \sum_{t=0}^{\infty} \beta^{t}\left(\prod_{k=1}^{t} d_{k}\right)^{-1}\left[\log \left(C_{h, t}-\gamma C_{t-1}\right)-\frac{l_{h, t}^{1+\eta}}{1+\eta}\right],
$$

subject to the budget constraint

$$
P_{t} C_{h, t}+B_{h, t}=W_{h, t}^{n} l_{h, t}+R_{t-1}^{n} B_{h, t-1}+T_{h, t},
$$

where $\beta \in(0,1)$ is the subjective discount factor, $\gamma \in[0,1]$ is the degree of external habit persistence in consumption preferences $\left(C_{t-1}\right.$ is the aggregate consumption in period $\left.t-1\right), \eta \geq 0$ is the inverse of the labor supply elasticity, $P_{t}$ is the price of final goods, $W_{h, t}^{n}$ is the nominal wage for household $h$, $R_{t}^{n}$ is the gross nominal interest rate, and $T_{h, t}$ is the sum of a lump-sum public transfer and profits received from firms. Following Eggertsson and Woodford (2003) and Christiano, Eichenbaum, and Rebelo (2011), a shock to the discount factor $d_{t}$ affects the weight of the utility in period $t+1$ relative to the one in period $t$. In the present model, this shock is broadly interpreted as a shock to aggregate demand. The log of the discount factor shock follows an AR(1) process

$$
\log d_{t}=\rho_{d} \log d_{t-1}+\varepsilon_{d, t},
$$

where $\rho_{d} \in[0,1)$ is an autoregressive coefficient and $\varepsilon_{d, t}$ is a normally distributed innovation with mean zero and standard deviation $\sigma_{d}$. The first-order conditions for optimal decisions on consumption and bond-holding are identical among households, and therefore become

$$
\begin{aligned}
\Lambda_{t} & =\frac{1}{C_{t}-\gamma C_{t-1}}, \\
\Lambda_{t} & =\frac{\beta}{d_{t}} R_{t} \mathbb{E}_{t} \frac{\Lambda_{t+1}}{\Pi_{t+1}},
\end{aligned}
$$

where $\Lambda_{t}$ is the marginal utility of consumption and $\Pi_{t}=P_{t} / P_{t-1}$ denotes gross inflation. 


\subsubsection{Wage setting}

A labor packer collects differentiated labor $\left\{l_{f, h, t}\right\}$ from each household $h$ and resells a labor package augmented by a CES aggregator $l_{f, t}=\left[\int_{0}^{1} l_{f, h, t}^{\left(\theta_{w}-1\right) / \theta_{w}} d h\right]^{\theta_{w} /\left(\theta_{w}-1\right)}$ to intermediate-good firms $f$, where $\theta_{w}>1$ represents the elasticity of substitution among labor varieties. Given the nominal wage for each household $W_{h, t}^{n}$, cost minimization yields a set of labor demand schedules $l_{f, h, t}=$ $\left(W_{h, t}^{n} / W_{t}^{n}\right)^{-\theta_{w}} l_{f, t}$ and the aggregate wage index $W_{t}^{n}=\left(\int_{0}^{1} W_{h, t}^{n} 1-\theta_{w} d h\right)^{1 /\left(1-\theta_{w}\right)}$.

Given the demand for labor by the labor packers, labor unions representing each household $h$ set nominal wages on a staggered basis, as in Erceg, Henderson, and Levin (2000). In each period, a fraction $1-\xi_{w} \in(0,1)$ of labor unions reoptimizes their nominal wages, whereas the remaining fraction $\xi_{w}$ indexes nominal wages to the economy's trend growth $\gamma_{a}$ and a weighted average of past inflation $\Pi_{t-1}$ and steady-state inflation $\bar{\Pi}$. The labor unions that reoptimize their nominal wages in the current period then maximize expected utility as follows

$$
\mathbb{E}_{t} \sum_{j=0}^{\infty} \xi_{w}^{j} \beta^{j}\left(\prod_{k=1}^{j} d_{k}\right)^{-1}\left[\frac{\gamma_{a}^{j} W_{h, t}^{n}}{P_{t+j}} \prod_{k=1}^{j}\left(\Pi_{t+k-1}^{\iota_{w}} \bar{\Pi}^{1-\iota_{w}}\right) \Lambda_{h, t+j} l_{h, t+j}-\frac{l_{h, t+j}^{1+\eta}}{1+\eta}\right],
$$

subject to the labor demand

$$
l_{f, h, t+j}=\left[\frac{\gamma_{a}^{j} W_{h, t}^{n}}{W_{t+j}^{n}} \prod_{k=1}^{j}\left(\Pi_{t+k-1}^{\iota_{w}} \bar{\Pi}^{1-\iota_{w}}\right)\right]^{-\theta_{w}} l_{f, t+j},
$$

where $l_{h, t}=\int_{0}^{1} l_{f, h, t} d f$ is the amount of labor supplied by each household $h$, and $\iota_{w} \in[0,1)$ is the weight of wage indexation to past inflation relative to steady-state inflation. The first-order condition for the reoptimized wage $W_{t}^{n, o}$ is given by

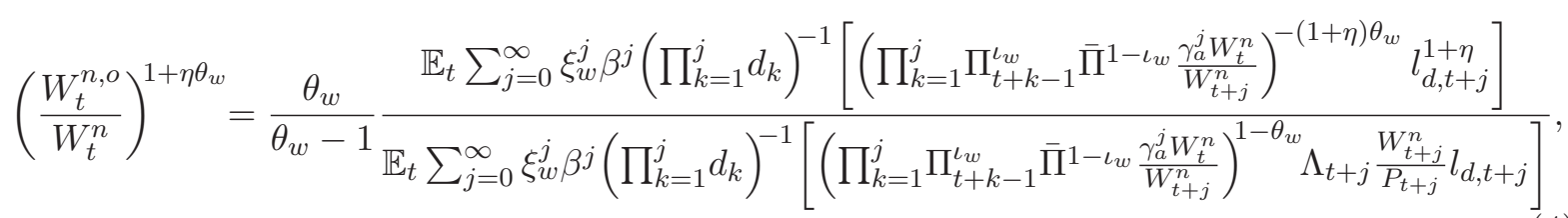

where $l_{d, t}=\int_{0}^{1} l_{f, t} d f$ is the total labor demand. The aggregate nominal wage index $W_{t}^{n}=$ $\left(\int_{0}^{1} W_{h, t}^{n} 1-\theta_{w} d h\right)^{1 /\left(1-\theta_{w}\right)}$ can be written as

$$
W_{t}^{n}=\left[\left(1-\xi_{w}\right)\left(W_{t}^{n, o}\right)^{1-\theta_{w}}+\xi_{w}\left(\Pi_{t-1}^{\iota_{w}} \bar{\Pi}^{1-\iota_{w}} \gamma_{a} W_{t-1}^{n}\right)^{1-\theta_{w}}\right]^{\frac{1}{1-\theta_{w}}} .
$$

\subsubsection{Firms}

The representative final-good firm produces output $Y_{t}$ under perfect competition by choosing a combination of intermediate inputs $\left\{Y_{f, t}\right\}$ so as to maximize profit $P_{t} Y_{t}-\int_{0}^{1} P_{f, t} Y_{f, t} d f$, subject to a 
CES production technology $Y_{t}=\left[\int_{0}^{1} Y_{f, t}^{\left(\theta_{p}-1\right) / \theta_{p}} d f\right]^{\theta_{p} /\left(\theta_{p}-1\right)}$, where $P_{f, t}$ is the price of intermediate good $f$ and $\theta_{p}>1$ denotes the elasticity of substitution among the variety of intermediate goods. The first-order condition for profit maximization yields the final-good firm's demand for each intermediate good $Y_{f, t}=\left(P_{f, t} / P_{t}\right)^{-\theta_{p}} Y_{t}$ and the aggregate price index $P_{t}=\left(\int_{0}^{1} P_{f, t}^{1-\theta_{p}} d f\right)^{1 /\left(1-\theta_{p}\right)}$.

Each intermediate-good firm $f$ produces a differentiated good $Y_{f, t}$ under monopolistic competition by choosing a labor input $l_{f, t}$, given the real wage $W_{t}=W_{t}^{n} / P_{t}$, and subject to the production function

$$
Y_{f, t}=A_{t} l_{f, t}
$$

where $A_{t}$ represents total factor productivity. The log of the productivity level follows a nonstationary stochastic process

$$
\log A_{t}=\log \gamma_{a}+\log A_{t-1}+a_{t},
$$

where $\log \gamma_{a}$ represents the steady-state growth rate of productivity and $a_{t}$ is a shock to the productivity growth. The productivity shock follows an AR(1) process

$$
a_{t}=\rho_{a} a_{t-1}+\varepsilon_{a, t}
$$

where $\rho_{a} \in[0,1)$ is an autoregressive coefficient and $\varepsilon_{a, t}$ is a normally distributed innovation with mean zero and standard deviation $\sigma_{a}$. Assuming the existence of a shock to real marginal cost $z_{t}$, which is interpreted as an inefficient cost-push shock, the first-order condition for cost minimization is given by ${ }^{4}$

$$
M C_{t}=\frac{W_{t}}{A_{t}} z_{t}
$$

The log of the cost-push shock follows an $\mathrm{AR}(1)$ process

$$
\log z_{t}=\rho_{z} \log z_{t-1}+\varepsilon_{z, t}
$$

where $\rho_{z} \in[0,1)$ is an autoregressive coefficient and $\varepsilon_{z, t}$ is a normally distributed innovation with mean zero and standard deviation $\sigma_{z}$.

In the face of the final-good firm's demand and marginal cost, the intermediate-good firms set the prices of their products on a staggered basis, as in Calvo (1983). In each period, a fraction $1-\xi_{p} \in(0,1)$ of intermediate-good firms reoptimizes their prices, whereas the remaining fraction $\xi_{p}$ indexes prices to a weighted average of past inflation $\Pi_{t-1}$ and steady-state inflation $\bar{\Pi}$. The

\footnotetext{
${ }^{4}$ The first-order condition also indicates that the real marginal cost $M C_{t}$ is identical across the intermediate-good firms.
} 
firms that reoptimize their prices in the current period then maximize expected profit as follows

$$
\mathbb{E}_{t} \sum_{j=0}^{\infty} \xi_{p}^{j} \beta^{j}\left(\prod_{k=1}^{j} d_{k}\right)^{-1} \frac{\Lambda_{t+j}}{\Lambda_{t}}\left[\frac{P_{f, t}}{P_{t+j}} \prod_{k=1}^{j}\left(\Pi_{t+k-1}^{\iota_{p}} \bar{\Pi}^{1-\iota_{p}}\right)-M C_{t+j}\right] Y_{f, t+j}
$$

subject to the final-good firm's demand

$$
Y_{f, t+j}=\left[\frac{P_{f, t}}{P_{t+j}} \prod_{k=1}^{j}\left(\Pi_{t+k-1}^{\iota_{p}} \bar{\Pi}^{1-\iota_{p}}\right)\right]^{-\theta_{p}} Y_{t+j}
$$

where $\iota_{p} \in[0,1)$ denotes the weight of price indexation to past inflation relative to steady-state inflation. The first-order condition for the reoptimized price $P_{t}^{o}$ is given by

$$
\frac{P_{t}^{o}}{P_{t}}=\frac{\theta}{\theta-1} \frac{\mathbb{E}_{t} \sum_{j=0}^{\infty} \xi_{p}^{j} \beta^{j}\left(\prod_{k=1}^{j} d_{k}\right)^{-1} \frac{\Lambda_{t+j}}{\Lambda_{t}}\left[\left(\prod_{k=1}^{j}\left[\left(\frac{\Pi_{t+k-1}}{\bar{\Pi}}\right)^{\iota_{p}} \frac{\bar{\Pi}}{\Pi_{t+k}}\right]\right)^{-\theta_{p}} M C_{t+j} Y_{t+j}\right]}{\mathbb{E}_{t} \sum_{j=0}^{\infty} \xi_{p}^{j} \beta^{j}\left(\prod_{k=1}^{j} d_{k}\right)^{-1} \frac{\Lambda_{t+j}}{\Lambda_{t}}\left[\left(\prod_{k=1}^{j}\left[\left(\frac{\Pi_{t+k-1}}{\bar{\Pi}}\right)^{\iota_{p}} \frac{\bar{\Pi}}{\Pi_{t+k}}\right]\right)^{1-\theta_{p}} Y_{t+j}\right]} .
$$

The final-good's price $P_{t}=\left(\int_{0}^{1} P_{f, t}^{1-\theta_{p}} d f\right)^{1 /\left(1-\theta_{p}\right)}$ can be written as

$$
P_{t}=\left[\left(1-\xi_{p}\right)\left(P_{t}^{o}\right)^{1-\theta_{p}}+\xi_{p}\left(\Pi_{t-1}^{\iota_{p}} \bar{\Pi}^{1-\iota_{p}} P_{t-1}\right)^{1-\theta_{p}}\right]^{\frac{1}{1-\theta_{p}}} .
$$

\subsubsection{Market clearing conditions}

The final-good market clearing condition is

$$
Y_{t}=C_{t},
$$

whereas the labor market clearing condition leads to

$$
l_{t}=\frac{\Delta_{p, t} \Delta_{w, t} Y_{t}}{A_{t}}
$$

where $l_{t}=\int_{0}^{1} \int_{0}^{1} l_{f, h, t} d f d h$ is the aggregate labor input, $\Delta_{p, t}=\int_{0}^{1}\left(P_{f, t} / P_{t}\right)^{-\theta_{p}} d f$ is price dispersion across the intermediate-good firms, and $\Delta_{w, t}=\int_{0}^{1}\left(W_{h, t}^{n} / W_{t}^{n}\right)^{-\theta_{w}} d h$ is wage dispersion across the labor unions. Equation (13) can be rewritten in terms of $l_{d, t}=\int_{0}^{1} l_{f, t} d f$ as

$$
l_{d, t}=\frac{\Delta_{p, t} Y_{t}}{A_{t}} .
$$

In the present model, the price and wage dispersion evolve according to

$$
\begin{aligned}
\Delta_{p, t} & =\left(1-\xi_{p}\right)\left(\frac{P_{t}^{o}}{P_{t}}\right)^{-\theta_{p}}+\xi_{p}\left(\frac{\Pi_{t}}{\bar{\Pi}}\right)^{\theta_{p}}\left(\frac{\Pi_{t-1}}{\bar{\Pi}}\right)^{-\iota_{p} \theta_{p}} \Delta_{p, t-1}, \\
\Delta_{w, t} & =\left(1-\xi_{w}\right)\left(\frac{W_{t}^{n, o}}{W_{t}^{n}}\right)^{-\theta_{w}}+\xi_{w}\left(\frac{\Pi_{t} W_{t}}{\overline{\bar{\Pi}} \gamma_{a} W_{t-1}}\right)^{\theta_{w}}\left(\frac{\Pi_{t-1}}{\bar{\Pi}}\right)^{-\iota_{w} \theta_{w}} \Delta_{w, t-1} .
\end{aligned}
$$




\subsubsection{Flexible wage and price equilibrium}

Natural output $Y_{t}^{*}$ and the natural rate of interest $R_{t}^{*}$ are defined as the levels that would prevail if both wages and prices were perfectly flexible with no cost-push shocks. Such a flexible wage and price equilibrium is obtained with $\xi_{w}=\xi_{p}=0, W_{h, t}^{n}=W_{t}^{n}, P_{f, t}=P_{t}$, and $z_{t}=1$ for all $h, f$, and $t$ in the model above and is characterized by the following equations:

$$
\begin{aligned}
& \left(Y_{t}^{*}-\gamma Y_{t-1}^{*}\right)\left(\frac{Y_{t}^{*}}{A_{t}}\right)^{\eta}=\mu A_{t}, \\
& R_{t}^{*}=\frac{d_{t}}{\beta}\left(\mathbb{E}_{t} \frac{Y_{t}^{*}-\gamma Y_{t-1}^{*}}{Y_{t+1}^{*}-\gamma Y_{t}^{*}}\right)^{-1},
\end{aligned}
$$

where $\mu=\frac{\theta_{w}-1}{\theta_{w}} \frac{\theta_{p}-1}{\theta_{p}}$ is the product of price and wage markups. Thus, the law of motion for natural output $Y_{t}^{*}$ is determined by (17), given the sequence of total factor productivity $A_{t}$. The natural rate of interest $R_{t}^{*}$ is determined by (18), with the sequences of natural output $Y_{t}^{*}$ and the discount factor shock $d_{t}$.

\subsubsection{Central bank}

A monetary policy rule is specified as

$$
R_{t}^{n}=\max \left[\widehat{R}_{t}^{n}, 1\right]
$$

where

$$
\widehat{R}_{t}^{n}=\left(\widehat{R}_{t-1}^{n}\right)^{\phi_{r}}\left[\bar{R} \bar{\Pi}\left(\frac{\Pi_{t}}{\bar{\Pi}}\right)^{\phi_{\pi}}\left(\frac{Y_{t}}{Y_{t}^{*}}\right)^{\phi_{y}}\right]^{1-\phi_{r}} \exp \left(\varepsilon_{r, t}\right) .
$$

$\widehat{R}_{t}^{n}$ denotes the hypothetical nominal interest rate that the central bank would set according to a Taylor (1993) type monetary policy rule, where $\bar{R}$ is the steady-state gross real interest rate, $\phi_{r} \in[0,1)$ is the policy-smoothing parameter, and $\phi_{\pi} \geq 0$ and $\phi_{y} \geq 0$ are the degrees of the interest rate policy response to inflation and the output gap. The output gap is defined as a deviation of actual output from its natural level. $\varepsilon_{r, t}$ is a monetary policy shock, which is normally distributed with mean zero and standard deviation $\sigma_{r}$. The max function in (19) constrains the nominal interest rate to be greater than or equal to zero. If $\widehat{R}_{t}^{n}>1$, the ZLB constraint is not imposed, i.e., $R_{t}^{n}=\widehat{R}_{t}^{n}$. If $\widehat{R}_{t}^{n} \leq 1$, the ZLB is binding, i.e., $R_{t}^{n}=1$.

\subsubsection{Equilibrium}

An equilibrium is given by the sequences $\left\{Y_{t}, C_{t}, \Lambda_{t}, W_{t}, W_{t}^{n}, W_{t}^{n, o}, l_{t}, l_{d, t}, M C_{t}, \Pi_{t}, P_{t}, P_{t}^{o}, \Delta_{p, t}, \Delta_{w, t}\right.$, $\left.Y_{t}^{*}, R_{t}^{*}, R_{t}^{n}, \widehat{R}_{t}^{n}, d_{t}, A_{t}, a_{t}, z_{t}\right\}_{t=0}^{\infty}$ satisfying the equilibrium conditions (1)-(20) and two definitional equations, $W_{t}=W_{t}^{n} / P_{t}$ and $\Pi_{t}=P_{t} / P_{t-1}$. 
Because total factor productivity $A_{t}$ is nonstationary, as specified by (6), we rewrite the equilibrium conditions in terms of stationary variables detrended by $A_{t}$, as follows: $y_{t}=Y_{t} / A_{t}, c_{t}=C_{t} / A_{t}$, $\lambda_{t}=\Lambda_{t} A_{t}, w_{t}=W_{t} / A_{t}, w_{t}^{n}=W_{t}^{n} / A_{t}, w_{t}^{n, o}=W_{t}^{n, o} / A_{t}, m c_{t}=M C_{t} / A_{t}$, and $y_{t}^{*}=Y_{t}^{*} / A_{t}$, so that we can derive a nonstochastic steady state for the detrended variables.

\subsection{Estimation of parameters}

To parameterize the model, we estimate a linearized version of the model using four U.S. quarterly time series: the per capita real GDP growth rate $\left(100 \Delta \log G D P_{t}\right)$, the inflation rate of the GDP implicit price deflator $\left(100 \Delta \log P G D P_{t}\right)$, the federal funds rate $\left(F F_{t}\right)$, and the log of hours worked $\left(100 \log H_{t}\right)$. The sample period is from 1983:I to 2007:IV. The beginning of the sample is determined to exclude the possibility of equilibrium indeterminacy, based on the results of Clarida, Galí, and Gertler (2000) and Lubik and Schorfheide (2004). The end of the sample is selected to avoid the periods of economic instability arising from the financial turmoil and the subsequent virtually zero nominal interest rates. The linearized equilibrium conditions and observation equations are presented in Appendix A.

In the estimation, we employ Bayesian methods. The prior distributions of the parameters are presented in the second to fourth columns of Table 1. For most of the parameters, each prior mean is set at the corresponding prior mean used in Smets and Wouters (2007). The prior mean of the policy-smoothing parameter $\phi_{r}$ is set at 0.5, which is lower than that in Smets and Wouters (2007) because a higher value of the estimated $\phi_{r}$ would lead to a nonconvergence problem in solving our nonlinear model. ${ }^{5}$ As for the steady-state rates of output growth, inflation, and real interest $(\bar{a}, \bar{\pi}$, $\bar{r})$, the priors are centered at the sample mean. For the standard deviations of the shocks $\left(100 \sigma_{d}\right.$, $100 \sigma_{a}, 100 \sigma_{z}, 100 \sigma_{r}$ ), we assign inverse-gamma distributions with a mean of 0.5 and a standard deviation of 2.0 .

The posterior mode and standard deviation of each parameter are reported in the last two columns of Table 1. In the subsequent analysis, the parameters are fixed at the posterior mode.

\subsection{Nonlinear solution and filtering}

The model is solved in a fully nonlinear and stochastic setting with the ZLB constraint on the nominal interest rate using a projection method. The model has seven endogenous state variables (output $y_{-1}$, inflation $\Pi_{-1}$, the real wage $w_{-1}$, the hypothetical nominal interest rate $\widehat{R}_{-1}^{n}$, price

\footnotetext{
${ }^{5}$ For the same reason, relatively tight priors are used for the parameters that determine the persistency of endogenous variables in the model.
} 
dispersion $\Delta_{p,-1}$, wage dispersion $\Delta_{w,-1}$, and natural output $y_{-1}^{*}$ ) and four exogenous shocks (the discount factor shock $d$, the productivity shock $A$, the cost-push shock $z$, and the monetary policy shock $\left.\varepsilon_{r}\right) .{ }^{6}$ The policy functions satisfying the detrended equilibrium conditions can be written as

$$
\mathbb{S}=h\left(\mathbb{S}_{-1}, \tau\right),
$$

where $\mathbb{S}_{-1}=\left[y_{-1}, \Pi_{-1}, w_{-1}, \widehat{R}_{-1}^{n}, \Delta_{p,-1}, \Delta_{w,-1}, y_{-1}^{*}\right]^{\prime}$ and $\tau=\left[d, A, z, \varepsilon_{r}\right]^{\prime}$.

Because of the high dimensionality of the state variables, it is computationally very expensive to apply a conventional projection method that uses the tensor product of one-dimensional polynomials. In this regard, we employ a projection method equipped with a Smolyak algorithm, in which a relatively small number of grid points are selected on the basis of their potential importance for the quality of approximation. Moreover, we adopt a more efficient Smolyak algorithm developed by Judd, Maliar, Maliar, and Valero (2014). Specifically, we construct the unidimensional disjoint sets of grid points of the endogenous state variables $\mathbb{S}_{-1}$ instead of the conventional nested sets to avoid repetitions of grid points. Then, we compute projection functions onto the grid points with interpolation coefficients and a Chebyshev family of orthogonal basis functions. ${ }^{7}$ The grid points obtained by this algorithm are sparse; therefore, the algorithm is more likely to be free from the curse of dimensionality. The details of the solution method are described in Appendix B.

According to an artificial sample of 40,000 periods simulated from the nonlinear solution of the model, the economy is at the ZLB for 11.8 percent of quarters, and the average duration of ZLB spells is 4.3 quarters. These statistics indicate that our model economy is more frequently constrained by the ZLB and that the average duration of ZLB spells is longer than the simulation results in the previous studies that employ nonlinear New Keynesian models, such as FernándezVillaverde, Gordon, Guerrón-Quintana, and Rubio-Ramírez (2015) and Gust, Herbst, López-Salido, and Smith (2017). ${ }^{8}$

\footnotetext{
${ }^{6}$ Time subscripts are omitted in this subsection and Appendix B as the policy functions are time-independent objects.

${ }^{7}$ To obtain the interpolation coefficients, we follow Judd, Maliar, Maliar, and Valero (2014) and use a Lagrange interpolation method, whereas Malin, Krueger, and Kubler (2011) use the closed-form formula to obtain approximated functions.

${ }^{8}$ Fernández-Villaverde, Gordon, Guerrón-Quintana, and Rubio-Ramírez (2015) simulate a small-scale model calibrated for the U.S. economy and show that the economy spends 5.5 percent of quarters at the ZLB and that the average duration at the ZLB is 2.1 quarters. Gust, Herbst, López-Salido, and Smith (2017) estimate a medium-scale model in a nonlinear setting using U.S. data from 1983:Q1 to 2014:Q1, and the simulation of their estimated model demonstrates that the economy is at the ZLB for about 4 percent of quarters on average and that the average duration of the ZLB spells is just over 3.5 quarters.
} 
We apply a particle filter as developed by Fernández-Villaverde and Rubio-Ramírez (2007) to extract the sequence of the state variables and then compute the estimates of natural output and the natural interest rate. ${ }^{9}$ The data used for filtering is the same as those used for the parameter estimation in Section 2.2, but the period over which the filter is run is extended to 2016:III. To facilitate the use of the particle filter, measurement errors are added in the observation equations. The measurement errors of output growth, inflation, the nominal interest rate, and hours worked are respectively set to be $20,20,10$, and 5 percent of their standard deviations in the data over the sample from 1983:I to 2016:III so that the smoothed (two-sided) estimates of the observables can track the data reasonably well, as shown in Figure 1. We use 20,000 particles and confirmed that any further increase in the number of particles delivered almost the same results as those presented below.

\section{Results}

This section presents the estimate of the natural interest rate based on the nonlinear model and compares it with the estimate based on its linear counterpart. To understand the cause of the difference between the two estimates, we investigate how the natural rate of interest is identified in each case. Moreover, we consider a quasi-linear model, in which the ZLB constraint is imposed but all the equilibrium conditions are linearized, and examine its usefulness for estimating the natural rate.

\subsection{Estimated natural rate of interest}

The thick line in Figure 2 shows the smoothed mean estimate of the natural rate of interest on an annualized basis. The estimated natural rate measure peaked around 15 percent in the late 1980s and the late 1990s, fell to less than -10 percent in the aftermath of the global financial crisis, and thereafter remained negative. Although the overall cyclical movements in the natural rate are very similar to those estimated by Barsky, Justiniano, and Melosi (2014), their estimate of the natural rate exhibits less variability than ours; i.e., the peak and bottom of their estimate are around 12 percent and -7 percent, respectively. This difference is attributable to the fact that Barsky, Justiniano, and Melosi (2014) employ a model with capital accumulation, whereas our model excludes it. Inclusion of capital would reduce the volatility of shocks and make the natural

\footnotetext{
${ }^{9}$ For a textbook treatment of a particle filter, see Fernández-Villaverde, Rubio-Ramírez, and Schorfheide (2016) or Herbst and Schorfheide (2015).
} 
rate less volatile, as explained by Cúrdia, Ferrero, Ng, and Tambalotti (2015). ${ }^{10}$

The primary objective of this paper is to examine how and to what extent nonlinearity, including the ZLB, affects the estimates of the natural rate of interest. To this end, we estimate the natural rate using a linear counterpart of the model, as in the previous studies, and compare it with the one obtained above. The thin line in Figure 2 is the smoothed mean estimate of the natural interest rate based on the linearized version of the model with the same parameters and data set as used in the nonlinear case. ${ }^{11}$ The figure indicates that the natural rate based on the linearized model is lower than that based on the nonlinear model. In particular, the difference is pronounced in the periods where the natural rate is low or negative.

To understand what causes the difference between the two estimates, we consider how the natural rate of interest is identified in each case. As addressed in Section 2.1, equation (17), i.e., $\left(Y_{t}^{*}-\gamma Y_{t-1}^{*}\right)\left(Y_{t}^{*} / A_{t}\right)^{\eta}=\mu A_{t}$, determines natural output $Y_{t}^{*}$, given the sequence of total factor productivity $A_{t}$ (or, equivalently, the productivity shock $a_{t}$ ). The natural rate of interest $R_{t}^{*}$ can be traced out from equation (18), i.e., $R_{t}^{*}=d_{t} / \beta\left[\mathbb{E}_{t}\left(Y_{t}^{*}-\gamma Y_{t-1}^{*}\right) /\left(Y_{t+1}^{*}-\gamma Y_{t}^{*}\right)\right]^{-1}$, with the sequences of natural output $Y_{t}^{*}$ and the discount factor shock $d_{t}$. Thus, the natural interest rate is pinned down by identifying the two shocks, $a_{t}$ and $d_{t}$.

In the linear model, the productivity shock $a_{t}$ is explicitly identified by the data on output and hours worked because detrending and log-linearizing the labor market clearing condition (13) yields $\tilde{y}_{t}=\tilde{l}_{t}$ and because the associated observation equations (abstracting from the observation errors) are $100 \Delta \log G D P_{t}=\bar{a}+\tilde{y}_{t}-\tilde{y}_{t-1}+a_{t}$ and $100 \log H_{t}=\bar{l}+\tilde{l}_{t}$, where $\bar{a}$ and $\bar{l}$ are the steadystate growth rate and hours worked, respectively, and the variables with represent percentage deviations from their steady-state values. In the nonlinear model, however, equation (13) contains the price and wage dispersion, $\Delta_{p, t}$ and $\Delta_{w, t}$, and can be written as $y_{t}=l_{t} /\left(\Delta_{p, t} \Delta_{w, t}\right)$ in detrended terms. These dispersion terms fluctuate so that $\Delta_{p, t} \geq 1$ and $\Delta_{w, t} \geq 1$, as the price and wage, respectively, deviate from the steady state. Thus, $y_{t}$ becomes lower than in the linear case where the dispersion terms are suppressed. Consequently, to satisfy the observation equation for output growth, $a_{t}$ can be identified as being larger in the nonlinear case. Higher productivity results in

\footnotetext{
${ }^{10}$ Cúrdia, Ferrero, Ng, and Tambalotti (2015) compare the estimated efficient real interest rates - the real interest rates that would prevail if the economy were perfectly competitive - using a small-scale New Keynesian model without capital and a medium-scale extension with capital and show that the latter model reduces the volatility of the rate.

${ }^{11}$ In the case of the linear model, the smoothed estimates of model variables could be computed with a widely used linear solution method and Kalman filter. However, we apply the same projection method and particle filter as in the nonlinear case to avoid the possibility that differences in the solution and filtering methods could affect the estimate of the natural interest rate.
} 
the higher natural rate.

Identification of the discount factor shock $d_{t}$ is more complicated and influenced by the whole structure of the model. However, taking account of the finding that the two estimates of the natural interest rate differ from each other during the periods when the nominal interest rate is close to or bounded at zero, the existence of the ZLB, from which the linear model abstracts, possibly affects the identification of $d_{t}$ in the nonlinear model. The literature has established that the ZLB has a contractionary effect on the economy not only when the nominal interest is already binding at zero, but also when uncertainty exists about whether the ZLB will bind in the future. ${ }^{12}$ Although such a contractionary effect lowers expected output and inflation, the particle filter pegs actual output and inflation to the corresponding observables, which are the same in the linear and nonlinear cases. Then, in the nonlinear case, the discount factor shock $d_{t}$ must increase to satisfy the optimality conditions of households and firms. As a result, the natural rate increases.

To quantify the differences in the sequences of identified shocks, Figure 3 shows the smoothed mean estimates of the discount factor shocks $d_{t}$ and the productivity shocks $a_{t}$, in percentage terms, based on the nonlinear model (thick lines) and its linear counterpart (thin lines). The sequence of $d_{t}$ identified in the nonlinear model is substantially different from that identified in the linear model. In particular, the difference amounts to nearly two percent after the global financial crisis. On the other hand, the movements of $a_{t}$ are very similar between the models. Therefore, the difference in $d_{t}$ is the main source of the different estimates of the natural rate between the two cases.

Figure 4 confirms the mechanism behind the difference in the estimates of $d_{t}$, which is described above. In the figure, the smoothed estimates of expected inflation $E_{t} \log \Pi_{t+1}$ and expected output $E_{t} y_{t+1}$ (in detrended terms) are compared for the nonlinear case (thick lines) and the linear case (thin lines), in terms of percentage deviation from the steady state. In the case of the nonlinear setting, $E_{t} \log \Pi_{t+1}$ shifts downward to a large extent during the periods of the low nominal interest rate, whereas the downward shift in $E_{t} y_{t+1}$ is limited. The limited shift in $E_{t} y_{t+1}$ is ascribed to the consequence of the increased $d_{t}$, which has a direct positive effect on actual output through the Euler equation and accordingly raises the expected output.

The finding of the small difference in the estimated productivity shocks $a_{t}$ implies that the price and wage dispersion terms, $\Delta_{p, t}$ and $\Delta_{w, t}$, play a minor role in the nonlinear model. Indeed, as shown in Figure 5 , the smoothed estimates of $\Delta_{p, t}$ and $\Delta_{w, t}$ based on the nonlinear model exhibit little fluctuation, i.e., less than 0.1 percent at most, even though they are pronounced in the period

\footnotetext{
${ }^{12}$ Hills, Nakata, and Schmidt (2016) quantify such an uncertainty effect on inflation in the face of the interest rate lower bound.
} 
of the financial crisis when the ZLB constraint is binding.

\subsection{The natural rate of interest based on the quasi-linear model}

The analysis thus far suggests that the existence of the ZLB constraint plays a crucial role in identifying the natural rate of interest in a nonlinear setting, and that the inclusion of price and wage dispersion is relatively minor. However, we cannot deny the possibility that other nonlinearities affect the identification of the natural rate to a substantial degree. To investigate this possibility, we estimate the natural rate based on a quasi-linear version of the model, in which the ZLB constraint is imposed but all the equilibrium conditions are linearized, with the same parameters and data set as used in the preceding subsection, and we compare its estimate of the natural rate with the one based on the original nonlinear model.

Figure 6 depicts the smoothed mean estimate of the natural interest rate in the quasi-linear setting (thin line) along with the baseline estimate in the fully nonlinear setting (thick line). These two estimates almost coincide with each other throughout the sample period. Thus, nonlinearities other than the ZLB play a negligible role in identifying the natural rate. The same is confirmed by Figure 7, which shows the smoothed mean estimates of the discount factor shocks $d_{t}$ and the productivity shocks $a_{t}$, based on the quasi-linear model (thin lines) and the nonlinear model (thick lines). No substantial differences are found in each pair of the estimated shocks.

The result in the present subsection is parallel to that obtained by Hirose and Sunakawa (2015), who demonstrate that, first, a linearized DSGE model gives rise to biased estimates of parameters if the ZLB existing in a data generating process is omitted in estimation, but second, neglecting the other nonlinearities does not lead to biased estimates if the ZLB is not an issue. Therefore, from a practical perspective, a quasi-linear model incorporating the ZLB can be a possible substitute for a fully nonlinear model in estimating the natural rate measures.

\section{Concluding Remarks}

This paper has estimated the natural rate of interest in a nonlinear New Keynesian model using U.S. macroeconomic data and compared it with the rate estimated with the model's linear counterpart. We have found that the natural rate based on the nonlinear model is substantially higher than that based on the linear model, particularly in the periods when the nominal interest rate is close to or bounded at zero. This difference is explained by a contractionary effect of the ZLB, which is considered only in the nonlinear model. Although other nonlinearities such as price and 
wage dispersion potentially affect the estimates of the natural rate, we have demonstrated that their effects are relatively minor. Our findings suggest the importance of considering the ZLB in the estimation of natural rate measures.

Whereas the present paper employs an empirically richer DSGE model than the prototypical New Keynesian model, existing studies, including Barsky, Justiniano, and Melosi (2014), Cúrdia, Ferrero, Ng, and Tambalotti (2015), Edge, Kiley, and Laforte (2008), Del Negro, Giannone, Giannoni, and Tambalotti (2017), and Justiniano and Primiceri (2010) have estimated the natural interest rate using medium-scale DSGE models with capital accumulation. Our analysis could be extended to exploit such a medium-scale model so that the estimated natural rate would be comparable to the rates obtained in these studies. We conjecture that our results regarding the higher estimate of the natural rate in a nonlinear setting would still hold, even if we extended our model to a larger scale, because the main mechanism through which nonlinearities can affect the identification of the natural rate remains unchanged. 


\section{Appendix}

\section{A Linearized Equilibrium Conditions and Observation Equations}

Log-linearizing the detrended equilibrium conditions around the nonstochastic steady state, and rearranging the resulting equations, yields

$$
\begin{aligned}
\tilde{y}_{t} & =\frac{\gamma_{a}}{\gamma_{a}+\gamma}\left(\mathbb{E}_{t} \tilde{y}_{t+1}+\mathbb{E}_{t} a_{t+1}\right)+\frac{\gamma}{\gamma_{a}+\gamma}\left(\tilde{y}_{t-1}-a_{t}\right)-\frac{\gamma_{a}-\gamma}{\gamma_{a}+\gamma}\left(\tilde{R}_{t}-\mathbb{E}_{t} \tilde{\Pi}_{t+1}-\tilde{d}_{t}\right), \\
\tilde{w}_{t} & =\tilde{w}_{t-1}-\tilde{\Pi}_{t}+\iota_{w} \tilde{\Pi}_{t-1}-a_{t}+\beta\left(\mathbb{E}_{t} \tilde{w}_{t+1}-\tilde{w}_{t}+\mathbb{E}_{t} \tilde{\Pi}_{t+1}-\iota_{w} \tilde{\Pi}_{t}+\mathbb{E}_{t} a_{t+1}\right) \\
& +\frac{\left(1-\xi_{w}\right)\left(1-\xi_{w} \beta\right)}{\xi_{w}\left(1+\eta \theta_{w}\right)}\left[\eta \tilde{l}_{t}+\frac{1}{\gamma_{a}+\gamma}\left(\gamma_{a} \tilde{y}_{t}-\gamma \tilde{y}_{t-1}+\gamma a_{t}\right)-\widetilde{w}_{t}\right] \\
\tilde{y}_{t} & =\tilde{l}_{t}, \\
\tilde{\Pi}_{t} & =\frac{\beta}{1+\beta \iota_{p}} \mathbb{E}_{t} \tilde{\Pi}_{t+1}+\frac{\iota_{p}}{1+\beta \iota_{p}} \tilde{\Pi}_{t-1}+\frac{\left(1-\xi_{p}\right)\left(1-\xi_{p} \beta\right)}{\xi_{p}\left(1+\beta \iota_{p}\right)}\left(\tilde{w}_{t}+\tilde{z}_{t}\right), \\
\tilde{y}_{t}^{*} & =\frac{\gamma}{\gamma_{a}(1+\eta)-\gamma \eta}\left(\tilde{y}_{t-1}^{*}-a_{t}\right), \\
\tilde{R}_{t} & =\phi_{r} \tilde{R}_{t-1}+\left(1-\phi_{r}\right)\left[\phi_{\pi} \tilde{\Pi}_{t}+\phi_{y}\left(\tilde{y}_{t}-\tilde{y}_{t}^{*}\right)\right]+\varepsilon_{r, t}, \\
\tilde{d}_{t} & =\rho_{d} \tilde{d}_{t-1}+\varepsilon_{d, t} \\
a_{t} & =\rho_{a} a_{t-1}+\varepsilon_{a, t} \\
\tilde{z}_{t} & =\rho_{z} \tilde{z}_{t-1}+\varepsilon_{z, t}
\end{aligned}
$$

where the variables with $\sim$ represent percentage deviations from their steady-state values.

The observation equations are

$$
\left[\begin{array}{c}
100 \Delta \log G D P_{t} \\
100 \Delta \log P G D P_{t} \\
F F_{t} \\
100 \log H_{t}
\end{array}\right]=\left[\begin{array}{c}
\bar{a} \\
\bar{\pi} \\
\bar{r}+\bar{\pi} \\
\bar{l}
\end{array}\right]+\left[\begin{array}{c}
\tilde{y}_{t}-\tilde{y}_{t-1}+a_{t} \\
\tilde{\Pi}_{t} \\
\tilde{R}_{t} \\
\tilde{l}_{t}
\end{array}\right],
$$

where $\bar{a}=100 \log \gamma_{a}, \bar{\pi}=100 \log \bar{\Pi}, \bar{r}=100 \log \bar{R}\left(=100 \log \left(\gamma_{a} / \beta\right)\right)$, and $\bar{l}$ are, respectively, the steady-state growth rate, the inflation rate, the real interest rate, and hours worked. 


\section{B Nonlinear Solution Method}

\section{B.1 Recursive forms of the price and wage setting equations}

After detrending, the equilibrium conditions (10) and (4) can be written in the following recursive forms:

$$
\begin{aligned}
\frac{P_{t}^{o}}{P_{t}} & =\frac{S_{p, t}}{F_{p, t}} \\
S_{p, t} & =\theta_{p} w_{t} z_{t}+\xi_{p} \beta d_{t}^{-1} \mathbb{E}_{t}\left[\left(\frac{\Pi_{t+1}}{\bar{\Pi}}\right)\left(\frac{\Pi_{t}}{\bar{\Pi}}\right)^{-\iota_{p}}\right]^{\theta_{p}} \frac{y_{t+1}}{y_{t}} \frac{\lambda_{t+1}}{\lambda_{t}} S_{p, t+1}, \\
F_{p, t} & =\left(\theta_{p}-1\right)+\xi_{p} \beta d_{t}^{-1} \mathbb{E}_{t}\left[\left(\frac{\Pi_{t+1}}{\bar{\Pi}}\right)\left(\frac{\Pi_{t}}{\bar{\Pi}}\right)^{-\iota_{p}}\right]^{\theta_{p}-1} \frac{y_{t+1}}{y_{t}} \frac{\lambda_{t+1}}{\lambda_{t}} F_{p, t+1}, \\
\left(\frac{W_{t}^{n, o}}{W_{t}^{n}}\right)^{1+\eta \theta_{w}} & =\frac{S_{w, t}}{F_{w, t}} \\
S_{w, t} & =\theta_{w} l_{d, t}^{\eta} \lambda_{t}^{-1}+\xi_{w} \beta d_{t}^{-1} \mathbb{E}_{t}\left[\left(\frac{\Pi_{w, t+1}}{\bar{\Pi}} \exp \left(a_{t+1}\right)\right)\left(\frac{\Pi_{t}}{\bar{\Pi}}\right)^{-\iota_{w}}\right]^{(1+\eta) \theta_{w}} \frac{l_{d, t+1}}{l_{d, t}} \frac{\lambda_{t+1}}{\lambda_{t}} S_{w, t+1}, \\
F_{w, t} & =\left(\theta_{w}-1\right) w_{t}+\xi_{w} \beta d_{t}^{-1} \mathbb{E}_{t}\left[\left(\frac{\Pi_{w, t+1}}{\bar{\Pi}} \exp \left(a_{t+1}\right)\right)\left(\frac{\Pi_{t}}{\bar{\Pi}}\right)^{-\iota_{w}}\right]^{\theta_{w}-1} \frac{l_{d, t+1}}{l_{d, t}} \frac{\lambda_{t+1}}{\lambda_{t}} F_{w, t+1},
\end{aligned}
$$

where $\Pi_{w, t}=\Pi_{t} w_{t} / w_{t-1}$ and $l_{d, t}=\Delta_{p, t} y_{t}$.

\section{B.2 Solution algorithm}

To solve for the policy functions on each grid point of the state space $\left(\mathbb{S}_{-1}, \tau\right)$, we follow the approach in Christiano and Fisher (2000) and Gust, Herbst, López-Salido, and Smith (2017). We consider the regime-specific policy functions $h_{x, i}\left(\mathbb{S}_{-1}, \tau\right)$ for $x \in\left\{y, \Pi, w, \widehat{R}^{n}, \Delta_{p}, \Delta_{w}, y^{*}, \Pi_{w}, l_{d}\right\}$ and $i \in\{1,2\}$, for which the index $i$ is associated with the interest-rate regime in which the hypothetical nominal interest rate $\widehat{R}^{n}$ is either above or below the lower bound. Specifically, the policy functions are defined as weighted averages of the regime-specific functions as follows

$$
x=h_{x}\left(\mathbb{S}_{-1}, \tau\right)=h_{x, 1}\left(\mathbb{S}_{-1}, \tau\right) 1_{\left\{h_{\widehat{R}^{n}, 1}\left(\mathbb{S}_{-1}, \tau\right)>1\right\}}+h_{x, 2}\left(\mathbb{S}_{-1}, \tau\right) 1_{\left\{h_{\widehat{R}^{n}, 1}\left(\mathbb{S}_{-1}, \tau\right) \leq 1\right\}},
$$

where $1_{\{D\}}$ is the indicator function that equals one if the condition $D$ is true and zero otherwise, and $h_{\widehat{R}^{n}, i}\left(\mathbb{S}_{-1}, \tau\right), i=1,2$ are

$$
\begin{aligned}
& h_{\widehat{R}^{n}, 1}\left(\mathbb{S}_{-1}, \tau\right)=\left(\widehat{R}_{-1}\right)^{\phi_{r}}\left[\bar{R} \bar{\Pi}\left(\frac{h_{\Pi, 1}\left(\mathbb{S}_{-1}, \tau\right)}{\bar{\Pi}}\right)^{\phi_{\pi}}\left(\frac{h_{y, 1}\left(\mathbb{S}_{-1}, \tau\right)}{h_{y^{*}, 1}\left(\mathbb{S}_{-1}, \tau\right)}\right)^{\phi_{y}}\right]^{1-\phi_{r}} \exp \left(\varepsilon_{r}\right), \\
& h_{\widehat{R}^{n}, 2}\left(\mathbb{S}_{-1}, \tau\right)=1 .
\end{aligned}
$$


Given the stochastic processes of $\tau$, the equilibrium conditions of the model can be expressed with the regime-specific functions in each regime $i=1,2$ as follows:

$$
\begin{aligned}
& \frac{1}{\mathcal{W}_{i}\left(\mathbb{S}_{-1}, \tau\right)}=\beta d^{-1} h_{\widehat{R}^{n}, i}\left(\mathbb{S}_{-1}, \tau\right) \int_{\tau^{\prime}}\left\{\frac{\Phi\left(\tau^{\prime} \mid \tau\right)}{\mathcal{W}\left(\mathbb{S}, \tau^{\prime}\right) h_{\Pi}\left(\mathbb{S}, \tau^{\prime}\right)}\right\} \\
& S_{p, i}\left(\mathbb{S}_{-1}, \tau\right)=\theta_{p} \mathcal{X}_{i}\left(\mathbb{S}_{-1}, \tau\right) z \\
& +\xi_{p} \beta d^{-1} \int_{\tau^{\prime}} \Phi\left(\tau^{\prime} \mid \tau\right)\left\{\left[\left(\frac{h_{\Pi}\left(\mathbb{S}, \tau^{\prime}\right)}{\bar{\Pi}}\right)\left(\frac{h_{\Pi, i}\left(\mathbb{S}_{-1}, \tau\right)}{\bar{\Pi}}\right)^{-\iota_{p}}\right]^{\theta_{p}} \frac{h_{y}\left(\mathbb{S}, \tau^{\prime}\right)}{h_{y, i}\left(\mathbb{S}_{-1}, \tau\right)} \frac{\mathcal{W}_{i}\left(\mathbb{S}_{-1}, \tau\right)}{\mathcal{W}\left(\mathbb{S}, \tau^{\prime}\right)} S_{p}\left(\mathbb{S}, \tau^{\prime}\right)\right\}, \\
& F_{p, i}\left(\mathbb{S}_{-1}, \tau\right)=\left(\theta_{p}-1\right) \\
& +\xi_{p} \beta d^{-1} \int_{\tau^{\prime}} \Phi\left(\tau^{\prime} \mid \tau\right)\left\{\left[\left(\frac{h_{\Pi}\left(\mathbb{S}, \tau^{\prime}\right)}{\bar{\Pi}}\right)\left(\frac{h_{\Pi, i}\left(\mathbb{S}_{-1}, \tau\right)}{\bar{\Pi}}\right)^{-\iota_{p}}\right]^{\theta_{p}-1} \frac{h_{y}\left(\mathbb{S}, \tau^{\prime}\right)}{h_{y, i}\left(\mathbb{S}_{-1}, \tau\right)} \frac{\mathcal{W}_{i}\left(\mathbb{S}_{-1}, \tau\right)}{\mathcal{W}\left(\mathbb{S}, \tau^{\prime}\right)} F_{p}\left(\mathbb{S}, \tau^{\prime}\right)\right\}, \\
& 1=\left(1-\xi_{p}\right)\left(\frac{S_{p, i}\left(\mathbb{S}_{-1}, \tau\right)}{F_{p, i}\left(\mathbb{S}_{-1}, \tau\right)}\right)^{1-\theta_{p}}+\xi_{p}\left[\left(\frac{h_{\Pi, i}\left(\mathbb{S}_{-1}, \tau\right)}{\bar{\Pi}}\right)\left(\frac{\Pi_{-1}}{\bar{\Pi}}\right)^{-\iota_{p}}\right]^{\theta_{p}-1}, \\
& h_{\Delta_{p}, i}\left(\mathbb{S}_{-1}, \tau\right)=\left(1-\xi_{p}\right)\left(\frac{S_{p, i}\left(\mathbb{S}_{-1}, \tau\right)}{F_{p, i}\left(\mathbb{S}_{-1}, \tau\right)}\right)^{-\theta_{p}}+\xi_{p}\left[\left(\frac{h_{\Pi, i}\left(\mathbb{S}_{-1}, \tau\right)}{\bar{\Pi}}\right)\left(\frac{\Pi_{-1}}{\bar{\Pi}}\right)^{-\iota_{p}}\right]^{\theta_{p}} \Delta_{p,-1}, \\
& S_{w, i}\left(\mathbb{S}_{-1}, \tau\right)=\theta_{w} h_{l_{d}, i}\left(\mathbb{S}_{-1}, \tau\right)^{\eta} \mathcal{W}_{i}\left(\mathbb{S}_{-1}, \tau\right) \\
& +\xi_{w} \beta d^{-1} \int_{\tau^{\prime}} \Phi\left(\tau^{\prime} \mid \tau\right)\left\{\left[\left(\frac{h_{\Pi_{w}}\left(\mathbb{S}, \tau^{\prime}\right) \exp \left(a^{\prime}\right)}{\bar{\Pi}}\right)\left(\frac{h_{\Pi, i}\left(\mathbb{S}_{-1}, \tau\right)}{\bar{\Pi}}\right)^{-\iota_{w}}\right]^{(1+\eta) \theta_{w}}\right. \\
& \left.\times \frac{h_{l_{d}}\left(\mathbb{S}, \tau^{\prime}\right)}{h_{l_{d}, i}\left(\mathbb{S}_{-1}, \tau\right)} \frac{\mathcal{W}_{i}\left(\mathbb{S}_{-1}, \tau\right)}{\mathcal{W}\left(\mathbb{S}, \tau^{\prime}\right)} S_{w}\left(\mathbb{S}, \tau^{\prime}\right)\right\}, \\
& F_{w, i}\left(\mathbb{S}_{-1}, \tau\right)=\left(\theta_{w}-1\right) \mathcal{X}_{i}\left(\mathbb{S}_{-1}, \tau\right) \\
& +\xi_{w} \beta d^{-1} \int_{\tau^{\prime}} \Phi\left(\tau^{\prime} \mid \tau\right)\left\{\left[\left(\frac{h_{\Pi_{w}}\left(\mathbb{S}, \tau^{\prime}\right) \exp \left(a^{\prime}\right)}{\bar{\Pi}}\right)\left(\frac{h_{\Pi, i}\left(\mathbb{S}_{-1}, \tau\right)}{\bar{\Pi}}\right)^{-\iota_{w}}\right]^{(1+\eta) \theta_{w}}\right. \\
& \left.\times \frac{h_{l_{d}}\left(\mathbb{S}, \tau^{\prime}\right)}{h_{l_{d}, i}\left(\mathbb{S}_{-1}, \tau\right)} \frac{\mathcal{W}_{i}\left(\mathbb{S}_{-1}, \tau\right)}{\mathcal{W}\left(\mathbb{S}, \tau^{\prime}\right)} F_{w}\left(\mathbb{S}, \tau^{\prime}\right)\right\} \text {, } \\
& 1=\left(1-\xi_{w}\right)\left(\frac{S_{w, i}\left(\mathbb{S}_{-1}, \tau\right)}{F_{w, i}\left(\mathbb{S}_{-1}, \tau\right)}\right)^{\frac{1-\theta_{w}}{1+\theta_{w}}}+\xi_{w}\left[\left(\frac{h_{\Pi_{w}, i}\left(\mathbb{S}_{-1}, \tau\right) \exp (a)}{\bar{\Pi}}\right)\left(\frac{\Pi_{-1}}{\bar{\Pi}}\right)^{-\iota_{w}}\right]^{\theta_{w}-1}, \\
& h_{\Delta_{w}, i}\left(\mathbb{S}_{-1}, \tau\right)=\left(1-\xi_{w}\right)\left(\frac{S_{w, i}\left(\mathbb{S}_{-1}, \tau\right)}{F_{w, i}\left(\mathbb{S}_{-1}, \tau\right)}\right)^{-\theta_{w}}+\xi_{w}\left[\left(\frac{h_{\Pi_{w}, i}\left(\mathbb{S}_{-1}, \tau\right) \exp (a)}{\bar{\Pi}}\right)\left(\frac{\Pi_{-1}}{\bar{\Pi}}\right)^{-\iota_{w}}\right]^{\theta_{w}} \Delta_{w,-1}, \\
& h_{w, i}\left(\mathbb{S}_{-1}, \tau\right)=\mathcal{X}_{i}\left(\mathbb{S}_{-1}, \tau\right), \\
& \mu=\left[h_{y^{*}, i}\left(\mathbb{S}_{-1}, \tau\right)-\frac{\gamma}{\gamma_{a}} y_{-1} \exp (-a)\right]\left[h_{y^{*}, i}\left(\mathbb{S}_{-1}, \tau\right)\right]^{\eta},
\end{aligned}
$$

where $\mathcal{W}_{i}\left(\mathbb{S}_{-1}, \tau\right)=h_{y, i}\left(\mathbb{S}_{-1}, \tau\right)-\left(\gamma / \gamma_{a}\right) y_{-1} \exp (-a), \mathcal{X}_{i}\left(\mathbb{S}_{-1}, \tau\right)=\left[h_{\Pi_{w}, i}\left(\mathbb{S}_{-1}, \tau\right) / h_{\Pi, i}\left(\mathbb{S}_{-1}, \tau\right)\right] w_{-1}$, 
$\Phi\left(\tau^{\prime} \mid \tau\right)$ is a conditional probability of $\tau^{\prime}$, given $\tau$, and $h_{\Pi}\left(\mathbb{S}, \tau^{\prime}\right), h_{y}\left(\mathbb{S}, \tau^{\prime}\right), h_{\Pi_{w}}\left(\mathbb{S}, \tau^{\prime}\right), h_{l_{d}}\left(\mathbb{S}, \tau^{\prime}\right)$, $S_{p}\left(\mathbb{S}, \tau^{\prime}\right), F_{p}\left(\mathbb{S}, \tau^{\prime}\right), S_{w}\left(\mathbb{S}, \tau^{\prime}\right), F_{w}\left(\mathbb{S}, \tau^{\prime}\right)$ and $\mathcal{W}\left(\mathbb{S}, \tau^{\prime}\right)$ are weighted averages of the regime-specific functions for the next period. ${ }^{13}$ Moreover, as in Gust, Herbst, López-Salido, and Smith (2017) and Hirose and Sunakawa (2015), we apply the following changes of variables:

$$
\begin{aligned}
& \mathcal{V}_{p, i}\left(\mathbb{S}_{-1}, \tau\right)=\int_{\tau^{\prime}} \Phi\left(\tau^{\prime} \mid \tau\right)\left\{\left[\left(\frac{h_{\Pi}\left(\mathbb{S}, \tau^{\prime}\right)}{\bar{\Pi}}\right)\left(\frac{h_{\Pi, i}\left(\mathbb{S}_{-1}, \tau\right)}{\bar{\Pi}}\right)^{-\iota_{p}}\right]^{\theta_{p}} \frac{h_{y}\left(\mathbb{S}, \tau^{\prime}\right) S_{p}\left(\mathbb{S}, \tau^{\prime}\right)}{h_{y, i}\left(\mathbb{S}_{-1}, \tau\right) \mathcal{W}\left(\mathbb{S}, \tau^{\prime}\right)}\right\}, \\
& \mathcal{K}_{p, i}\left(\mathbb{S}_{-1}, \tau\right)=\int_{\tau^{\prime}} \Phi\left(\tau^{\prime} \mid \tau\right)\left\{\left[\left(\frac{h_{\Pi}\left(\mathbb{S}, \tau^{\prime}\right)}{\bar{\Pi}}\right)\left(\frac{h_{\Pi, i}\left(\mathbb{S}_{-1}, \tau\right)}{\bar{\Pi}}\right)^{-\iota_{p}}\right]^{\theta_{p}-1} \frac{h_{y}\left(\mathbb{S}, \tau^{\prime}\right) F_{p}\left(\mathbb{S}, \tau^{\prime}\right)}{h_{y, i}\left(\mathbb{S}_{-1}, \tau\right) \mathcal{W}\left(\mathbb{S}, \tau^{\prime}\right)}\right\}, \\
& \mathcal{V}_{w, i}\left(\mathbb{S}_{-1}, \tau\right)=\int_{\tau^{\prime}} \Phi\left(\tau^{\prime} \mid \tau\right)\left\{\left[\left(\frac{h_{\Pi_{w}}\left(\mathbb{S}, \tau^{\prime}\right) \exp \left(a^{\prime}\right)}{\bar{\Pi}}\right)\left(\frac{h_{\Pi, i}\left(\mathbb{S}_{-1}, \tau\right)}{\bar{\Pi}}\right)^{-\iota_{w}}\right]^{(1+\eta) \theta_{w}} \frac{h_{l_{d}}\left(\mathbb{S}, \tau^{\prime}\right) S_{w}\left(\mathbb{S}, \tau^{\prime}\right)}{h_{l_{d}, i}\left(\mathbb{S}_{-1}, \tau\right) \mathcal{W}\left(\mathbb{S}, \tau^{\prime}\right)}\right\}, \\
& \mathcal{K}_{w, i}\left(\mathbb{S}_{-1}, \tau\right)=\int_{\tau^{\prime}} \Phi\left(\tau^{\prime} \mid \tau\right)\left\{\left[\left(\frac{h_{\Pi_{w}}\left(\mathbb{S}, \tau^{\prime}\right) \exp \left(a^{\prime}\right)}{\bar{\Pi}}\right)\left(\frac{h_{\Pi, i}\left(\mathbb{S}_{-1}, \tau\right)}{\bar{\Pi}}\right)^{-\iota_{w}}\right]^{\theta_{w}-1} \frac{h_{l_{d}}\left(\mathbb{S}, \tau^{\prime}\right) F_{w}\left(\mathbb{S}, \tau^{\prime}\right)}{h_{l_{d}, i}\left(\mathbb{S}_{-1}, \tau\right) \mathcal{W}\left(\mathbb{S}, \tau^{\prime}\right)}\right\} .
\end{aligned}
$$

Instead of approximating the policy functions $h_{x, i}\left(\mathbb{S}_{-1}, \tau\right)$ directly, we approximate the auxiliary functions, $\mathcal{W}_{i}\left(\mathbb{S}_{-1}, \tau\right), \mathcal{X}_{i}\left(\mathbb{S}_{-1}, \tau\right), \mathcal{V}_{p, i}\left(\mathbb{S}_{-1}, \tau\right), \mathcal{K}_{p, i}\left(\mathbb{S}_{-1}, \tau\right), \mathcal{V}_{w, i}\left(\mathbb{S}_{-1}, \tau\right)$, and $\mathcal{K}_{w, i}\left(\mathbb{S}_{-1}, \tau\right)$, using a projection method. ${ }^{14}$ To this end, we adopt a very efficient Smolyak algorithm developed by Judd, Maliar, Maliar, and Valero (2014). Specifically, we construct the unidimensional disjoint sets of grid points of the state variables instead of the conventional nested sets in order to avoid repetitions of grid points. Then, we compute projection functions onto the grid points with interpolation coefficients and a Chebyshev family of orthogonal basis functions. In the algorithm, the level of approximation is set at 2, following Fernández-Villaverde, Gordon, Guerrón-Quintana, and RubioRamírez (2015).

To obtain the interpolation coefficients of the approximated functions, we employ a fixed-point iteration with initial values of $\mathcal{W}_{i}^{(0)}\left(\mathbb{S}_{-1}, \tau\right), \mathcal{X}_{i}^{(0)}\left(\mathbb{S}_{-1}, \tau\right), \mathcal{V}_{p, i}^{(0)}\left(\mathbb{S}_{-1}, \tau\right), \mathcal{K}_{p, i}^{(0)}\left(\mathbb{S}_{-1}, \tau\right), \mathcal{V}_{w, i}^{(0)}\left(\mathbb{S}_{-1}, \tau\right)$ and $\mathcal{K}_{w, i}^{(0)}\left(\mathbb{S}_{-1}, \tau\right)$ on the grid points. In each iteration $j=1,2, \ldots, \mathcal{W}_{i}^{(j-1)}\left(\mathbb{S}_{-1}, \tau\right), \mathcal{X}_{i}^{(j-1)}\left(\mathbb{S}_{-1}, \tau\right)$, $\mathcal{V}_{p, i}^{(j-1)}\left(\mathbb{S}_{-1}, \tau\right), \mathcal{K}_{p, i}^{(j-1)}\left(\mathbb{S}_{-1}, \tau\right), \mathcal{V}_{w, i}^{(j-1)}\left(\mathbb{S}_{-1}, \tau\right)$, and $\mathcal{K}_{w, i}^{(j-1)}\left(\mathbb{S}_{-1}, \tau\right)$ determine $S_{p, i}\left(\mathbb{S}_{-1}, \tau\right), F_{p, i}\left(\mathbb{S}_{-1}, \tau\right)$,

\footnotetext{
${ }^{13}$ Note that these weighted averaged functions are affected by the possibility that the nominal interest rate can be bounded at zero in the next period. They also depend on the values of the policy functions in the current period, $x=h_{x, i}\left(\mathbb{S}_{-1}, \tau\right)$.

${ }^{14}$ We update the policy function $h_{w, i}\left(\mathbb{S}_{-1}, \tau\right)=\mathcal{X}_{i}\left(\mathbb{S}_{-1}, \tau\right)$ iteratively rather than solving the nonlinear equilibrium conditions to obtain $w$ at each grid point. When the algorithm converges, the obtained $w=h_{w, i}\left(\mathbb{S}_{-1}, \tau\right)$ satisfies the equilibrium conditions.
} 
$S_{w, i}\left(\mathbb{S}_{-1}, \tau\right)$ and $F_{w, i}\left(\mathbb{S}_{-1}, \tau\right)$ from ${ }^{15}$

$$
\begin{aligned}
S_{p, i}\left(\mathbb{S}_{-1}, \tau\right) & =\theta_{p} \mathcal{X}_{i}^{(j-1)}\left(\mathbb{S}_{-1}, \tau\right) z+\xi_{p} \beta d^{-1} \mathcal{W}_{i}^{(j-1)}\left(\mathbb{S}_{-1}, \tau\right) \mathcal{V}_{p, i}^{(j-1)}\left(\mathbb{S}_{-1}, \tau\right) \\
F_{p, i}\left(\mathbb{S}_{-1}, \tau\right) & =\left(\theta_{p}-1\right)+\xi_{p} \beta d^{-1} \mathcal{W}_{i}^{(j-1)}\left(\mathbb{S}_{-1}, \tau\right) \mathcal{K}_{p, i}^{(j-1)}\left(\mathbb{S}_{-1}, \tau\right) \\
S_{w, i}\left(\mathbb{S}_{-1}, \tau\right) & =\theta_{w} h_{l_{d}, i}\left(\mathbb{S}_{-1}, \tau\right)^{\eta} \mathcal{W}_{i}^{(j-1)}\left(\mathbb{S}_{-1}, \tau\right)+\xi_{w} \beta d^{-1} \mathcal{W}_{i}^{(j-1)}\left(\mathbb{S}_{-1}, \tau\right) \mathcal{V}_{w, i}^{(j-1)}\left(\mathbb{S}_{-1}, \tau\right) \\
F_{w, i}\left(\mathbb{S}_{-1}, \tau\right) & =\left(\theta_{w}-1\right) \mathcal{X}_{i}^{(j-1)}\left(\mathbb{S}_{-1}, \tau\right)+\xi_{w} \beta d^{-1} \mathcal{W}_{i}^{(j-1)}\left(\mathbb{S}_{-1}, \tau\right) \mathcal{K}_{w, i}^{(j-1)}\left(\mathbb{S}_{-1}, \tau\right) .
\end{aligned}
$$

Then, $h_{\Pi, i}\left(\mathbb{S}_{-1}, \tau\right), h_{\Pi_{w}, i}\left(\mathbb{S}_{-1}, \tau\right), h_{y, i}\left(\mathbb{S}_{-1}, \tau\right)$, and $h_{l_{d}, i}\left(\mathbb{S}_{-1}, \tau\right)$ are obtained by

$$
\begin{aligned}
h_{\Pi, i}\left(\mathbb{S}_{-1}, \tau\right) & =\Pi\left(\frac{\Pi_{-1}}{\bar{\Pi}}\right)^{\iota_{p}}\left(\xi_{p}^{-1}\left[1-\left(1-\xi_{p}\right)\left(\frac{S_{p, i}\left(\mathbb{S}_{-1}, \tau\right)}{F_{p, i}\left(\mathbb{S}_{-1}, \tau\right)}\right)^{1-\theta_{p}}\right]\right)^{\frac{1}{\theta_{p}-1}} \\
h_{\Pi_{w}, i}\left(\mathbb{S}_{-1}, \tau\right) & =\Pi \exp (-a)\left(\frac{\Pi_{-1}}{\bar{\Pi}}\right)^{\iota_{w}}\left(\xi_{w}^{-1}\left[1-\left(1-\xi_{w}\right)\left(\frac{S_{w, i}\left(\mathbb{S}_{-1}, \tau\right)}{F_{w, i}\left(\mathbb{S}_{-1}, \tau\right)}\right)^{\frac{1-\theta_{w}}{1+\theta_{w}}}\right]\right)^{\frac{1}{\theta_{w-1}}}, \\
h_{y, i}\left(\mathbb{S}_{-1}, \tau\right) & =\mathcal{W}_{i}^{(j-1)}\left(\mathbb{S}_{-1}, \tau\right)+\left(\gamma / \gamma_{a}\right) y_{-1} \exp (-a), \\
h_{l_{d}, i}\left(\mathbb{S}_{-1}, \tau\right) & =\left(\left(1-\xi_{p}\right)\left(\frac{S_{p, i}\left(\mathbb{S}_{-1}, \tau\right)}{F_{p, i}\left(\mathbb{S}_{-1}, \tau\right)}\right)^{-\theta_{p}}+\xi_{p}\left[\left(\frac{h_{\Pi, i}\left(\mathbb{S}_{-1}, \tau\right)}{\bar{\Pi}}\right)\left(\frac{\Pi_{-1}}{\bar{\Pi}}\right)^{-\iota_{p}}\right]^{\theta_{p}} \Delta_{p,-1}\right) h_{y, i}\left(\mathbb{S}_{-1}, \tau\right),
\end{aligned}
$$

whereas $h_{\Delta_{p}, i}\left(\mathbb{S}_{-1}, \tau\right), h_{\Delta_{w}, i}\left(\mathbb{S}_{-1}, \tau\right)$, and $h_{w, i}\left(\mathbb{S}_{-1}, \tau\right)$ follow from (A.3), (A.4), and (A.5), respectively. $h_{y^{*}, i}\left(\mathbb{S}_{-1}, \tau\right)$ is given by solving (A.6) using Newton's method. Finally, $h_{\widehat{R}^{n}, i}\left(\mathbb{S}_{-1}, \tau\right)$ is obtained by (A.1) and (A.2). Therefore, there is a one-to-one mapping from $\mathcal{W}_{i}^{(j-1)}\left(\mathbb{S}_{-1}, \tau\right)$, $\mathcal{X}_{i}^{(j-1)}\left(\mathbb{S}_{-1}, \tau\right), \mathcal{V}_{p, i}^{(j-1)}\left(\mathbb{S}_{-1}, \tau\right), \mathcal{K}_{p, i}^{(j-1)}\left(\mathbb{S}_{-1}, \tau\right), \mathcal{V}_{w, i}^{(j-1)}\left(\mathbb{S}_{-1}, \tau\right)$, and $\mathcal{K}_{w, i}^{(j-1)}\left(\mathbb{S}_{-1}, \tau\right)$ to $h_{x, i}\left(\mathbb{S}_{-1}, \tau\right)$ for all $x \in\left\{y, \Pi, w, \widehat{R}^{n}, \Delta_{p}, \Delta_{w}, y^{*}, \Pi_{w}, l_{d}\right\}$.

To describe the iterations, let $\hat{\mathcal{W}}^{\prime}=\mathcal{W}^{(j-1)}\left(\mathbb{S}, \tau^{\prime}\right), \hat{\mathcal{X}}^{\prime}=\mathcal{X}^{(j-1)}\left(\mathbb{S}, \tau^{\prime}\right), \hat{\mathcal{V}}_{p}^{\prime}=\mathcal{V}_{p}^{(j-1)}\left(\mathbb{S}, \tau^{\prime}\right)$, $\hat{\mathcal{K}}_{p}^{\prime}=\mathcal{K}_{p}^{(j-1)}\left(\mathbb{S}, \tau^{\prime}\right), \hat{\mathcal{V}}_{w}^{\prime}=\mathcal{V}_{w}^{(j-1)}\left(\mathbb{S}, \tau^{\prime}\right), \hat{\mathcal{K}}_{w}^{\prime}=\mathcal{K}_{w}^{(j-1)}\left(\mathbb{S}, \tau^{\prime}\right)$, where $\mathcal{W}^{(j-1)}\left(\mathbb{S}, \tau^{\prime}\right), \mathcal{X}^{(j-1)}\left(\mathbb{S}, \tau^{\prime}\right)$, $\mathcal{V}_{p}^{(j-1)}\left(\mathbb{S}, \tau^{\prime}\right), \mathcal{K}_{p}^{(j-1)}\left(\mathbb{S}, \tau^{\prime}\right), \mathcal{V}_{w}^{(j-1)}\left(\mathbb{S}, \tau^{\prime}\right)$, and $\mathcal{K}_{w}^{(j-1)}\left(\mathbb{S}, \tau^{\prime}\right)$ are weighted averages of the regimespecific functions for the next period, obtained in the $j-1$ th iteration. Then, in each iteration,

\footnotetext{
${ }^{15}$ For simplicity of notation, we omit the index $j$ from the functions except for $\mathcal{W}_{i}^{(j)}\left(\mathbb{S}_{-1}, \tau\right), \mathcal{X}_{i}^{(j)}\left(\mathbb{S}_{-1}, \tau\right)$, $\mathcal{V}_{p, i}^{(j)}\left(\mathbb{S}_{-1}, \tau\right), \mathcal{K}_{p, i}^{(j)}\left(\mathbb{S}_{-1}, \tau\right), \mathcal{V}_{w, i}^{(j)}\left(\mathbb{S}_{-1}, \tau\right)$, and $\mathcal{K}_{w, i}^{(j)}\left(\mathbb{S}_{-1}, \tau\right)$
} 
$\mathcal{W}_{i}^{(j)}\left(\mathbb{S}_{-1}, \tau\right), \mathcal{X}_{i}^{(j)}\left(\mathbb{S}_{-1}, \tau\right), \mathcal{V}_{p, i}^{(j)}\left(\mathbb{S}_{-1}, \tau\right), \mathcal{K}_{p, i}^{(j)}\left(\mathbb{S}_{-1}, \tau\right), \mathcal{V}_{w, i}^{(j)}\left(\mathbb{S}_{-1}, \tau\right)$ and $\mathcal{K}_{w, i}^{(j)}\left(\mathbb{S}_{-1}, \tau\right)$ are updated by

$$
\begin{aligned}
\mathcal{W}_{i}^{(j)}\left(\mathbb{S}_{-1}, \tau\right) & =\left[\beta d^{-1} h_{R, i}\left(\mathbb{S}_{-1}, \tau\right) \int_{\tau^{\prime}}\left\{\frac{\Phi\left(\tau^{\prime} \mid \tau\right)}{\hat{\mathcal{W}}^{\prime} \hat{\Pi}^{\prime}}\right\}\right]^{-1}, \\
\mathcal{X}_{i}^{(j)}\left(\mathbb{S}_{-1}, \tau\right) & =\left(h_{\Pi_{w}, i}\left(\mathbb{S}_{-1}, \tau\right) / h_{\Pi, i}\left(\mathbb{S}_{-1}, \tau\right)\right) w_{-1}, \\
\mathcal{V}_{p, i}^{(j)}\left(\mathbb{S}_{-1}, \tau\right) & =\int_{\tau^{\prime}} \Phi\left(\tau^{\prime} \mid \tau\right)\left\{\left[\left(\frac{\hat{\Pi}^{\prime}}{\bar{\Pi}}\right)\left(\frac{h_{\Pi, i}\left(\mathbb{S}_{-1}, \tau\right)}{\bar{\Pi}}\right)^{-\iota_{p}}\right]^{\theta_{p}} \frac{\hat{y}^{\prime}}{h_{y, i}\left(\mathbb{S}_{-1}, \tau\right)}\right. \\
& \left.\times\left(\theta_{p} \hat{\mathcal{X}}^{\prime} \hat{\mathcal{W}}^{\prime-1} z^{\prime}+\xi_{p} \beta d^{\prime-1} \hat{\mathcal{V}}_{p}^{\prime}\right)\right\} \\
& \left.\times\left(\left(\theta_{p}-1\right) \hat{\mathcal{W}}^{\prime-1}+\xi_{p} \beta d^{\prime-1} \hat{\mathcal{K}}_{p}^{\prime}\right)\right\}, \\
\mathcal{K}_{p, i}^{(j)}\left(\mathbb{S}_{-1}, \tau\right) & =\int_{\tau^{\prime}} \Phi\left(\tau^{\prime} \mid \tau\right)\left\{\left[\left(\frac{\hat{\Pi}^{\prime}}{\bar{\Pi}}\right)\left(\frac{h_{\Pi, i}\left(\mathbb{S}_{-1}, \tau\right)}{\bar{\Pi}}\right)^{-\iota_{p}}\right]^{\theta_{p}-1} \frac{\hat{y}^{\prime}}{h_{y, i}\left(\mathbb{S}_{-1}, \tau\right)}\right. \\
\mathcal{V}_{w, i}^{(j)}\left(\mathbb{S}_{-1}, \tau\right) & =\int_{\tau^{\prime}} \Phi\left(\tau^{\prime} \mid \tau\right)\left\{\left[\left(\frac{\hat{\Pi}_{w}^{\prime} \exp \left(a^{\prime}\right)}{\bar{\Pi}}\right)\left(\frac{h_{\Pi, i}\left(\mathbb{S}_{-1}, \tau\right)}{\bar{\Pi}}\right)^{-\iota_{w}}\right]^{(1+\eta) \theta_{w}} \frac{\hat{l}_{d}^{\prime}}{h_{\tilde{l}, i}\left(\mathbb{S}_{-1}, \tau\right)}\right. \\
& \left.\times\left(\theta_{w} \hat{l}_{d}^{\prime \eta}+\xi_{w} \beta d^{\prime-1} \hat{\mathcal{V}}_{w}^{\prime}\right)\right\}, \\
\mathcal{K}_{w, i}^{(j)}\left(\mathbb{S}_{-1}, \tau\right) & =\int_{\tau^{\prime}} \Phi\left(\tau^{\prime} \mid \tau\right)\left\{\left[\left(\frac{\hat{\Pi}_{w}^{\prime} \exp \left(a^{\prime}\right)}{\bar{\Pi}}\right)\left(\frac{h_{\Pi, i}\left(\mathbb{S}_{-1}, \tau\right)}{\bar{\Pi}}\right)^{-\iota_{w}}\right]^{\theta_{w}-1} \frac{\hat{l}_{d}^{\prime}}{h_{\tilde{l}, i}\left(\mathbb{S}_{-1}, \tau\right)}\right. \\
& \left.\left.\times\left(\theta_{w}-1\right) \hat{\mathcal{X}}^{\prime} \hat{\mathcal{W}}^{\prime-1}+\xi_{w} \beta d^{\prime-1} \hat{\mathcal{K}}_{w}^{\prime}\right)\right\},
\end{aligned}
$$

where the values of $\hat{\Pi}^{\prime}, \hat{\Pi}_{w}^{\prime}, \hat{y}^{\prime}$, and $\hat{l}_{d}^{\prime}$ are given by the aforementioned mapping from $\hat{\mathcal{W}}^{\prime}, \hat{\mathcal{X}}^{\prime}, \hat{\mathcal{V}}_{p}^{\prime}$, $\hat{\mathcal{K}}_{p}^{\prime}, \hat{\mathcal{V}}_{w}^{\prime}, \hat{\mathcal{K}}_{w}^{\prime}$. The integrals over $\tau^{\prime}$ are approximated by the Gauss-Hermite quadrature formula with four nodes. 


\section{References}

Andrés, Javier, J. David López-Salido, and Edward Nelson, 2009. "Money and the Natural Rate of Interest: Structural Estimates for the United States and the Euro Area." Journal of Economic Dynamics and Control, 33(3), 758-776.

Aruoba, S. Borağan, Pablo Cuba-Borda, and Frank Schorfheide, 2017. "Macroeconomic Dynamics Near the ZLB: A Tale of Two Countries." Review of Economic Studies, forthcoming.

Barsky, Robert, Alejandro Justiniano, and Leonardo Melosi, 2014. "The Natural Rate of Interest and Its Usefulness for Monetary Policy." American Economic Review: Papers 83 Proceedings, 104(5), 37-43.

Blanchard, Olivier, and Jordi Galí, 2007. "Real Wage Rigidities and the New Keynesian Model." Journal of Money, Credit and Banking, 39(s1), 35-65.

Boneva, Lena M., R. Anton Braun, and Yuichiro Waki, 2016. "Some Unpleasant Properties of Loglinearized Solutions When the Nominal Rate is Zero." Journal of Monetary Economics, 84, $216-232$.

Calvo, Guillermo A., 1983. "Staggered Prices in a Utility-Maximizing Framework." Journal of Monetary Economics, 12(3), 383-398.

Christiano, Lawrence J., Martin Eichenbaum, and Charles L. Evans, 2005. "Nominal Rigidities and the Dynamic Effects of a Shock to Monetary Policy." Journal of Political Economy, 113, 1-45.

Christiano, Lawrence, Martin Eichenbaum, and Sergio Rebelo, 2011. "When Is the Government Spending Multiplier Large?" Journal of Political Economy, 119(1), 78-121.

Cúrdia, Vasco. 2015. "Why So Slow? A Gradual Return for Interest Rates," Federal Reserve Bank of San Francisco Economic Letter, 2015-32, October 13, 2015.

Cúrdia, Vasco, Andrea Ferrero, Ging Cee Ng, and Andrea Tambalotti, 2015. "Has U.S. Monetary Policy Tracked the Efficient Interest Rate?" Journal of Monetary Economics, 70, 72-83.

Del Negro, Marco, Domenico Giannone, Marc P. Giannoni, and Andrea Tambalotti, 2017. "Safety, Liquidity, and the Natural Rate of Interest." Brookings Papers on Economic Activity, forthcoming. 
Edge, Rochelle M., Michael T. Kiley, and Jean-Philippe Laforte, 2008. "Natural Rate Measures in an Estimated DSGE Model of the U.S. Economy." Journal of Economic Dynamics and Control, 32(8), 2512-2535.

Eggertsson, Gauti B., and Michael Woodford, 2003. "The Zero Bound on Interest Rates and Optimal Monetary Policy." Brookings Papers on Economic Activity, 34(1), 139-235.

Erceg, Christopher J., Dale W. Henderson, and Andrew T. Levin, 2000. "Optimal Monetary Policy with Staggered Wage and Price Contracts." Journal of Monetary Economics, 46(2), 281-313.

Fernández-Villaverde, Jesús, Grey Gordon, Pablo A. Guerrón-Quintana, and Juan Rubio-Ramírez, 2015. "Nonlinear Adventures at the Zero Lower Bound." Journal of Economic Dynamics and Control, 57, 182-204.

Fernández-Villaverde, Jesús, and Juan F. Rubio-Ramírez, 2005. "Estimating Dynamic Equilibrium Economies: Linear Versus Nonlinear Likelihood." Journal of Applied Econometrics, 20(7), 891910.

Fernández-Villaverde, Jesús, and Juan F. Rubio-Ramírez, 2007. "Estimating Macroeconomic Models: A Likelihood Approach." Review of Economic Studies, 74(4), 1059-1087.

Fernández-Villaverde, Jesús, Juan F. Rubio-Ramírez, and Manuel S. Santos, 2006. "Convergence Properties of the Likelihood of Computed Dynamic Models." Econometrica, 74(1), 93-119.

Fernández-Villaverde, Jesús, Juan Rubio-Ramírez, and Frank Schorfheide, 2016. "Solution and Estimation Methods for DSGE Models." In Handbook of Macroeconomics, edited by John B. Taylor and Harald Uhlig, Vol. 2A, pp. 527-724. North-Holland, Amsterdam.

Galí, Jordi. 2008. Monetary Policy, Inflation, and the Business Cycle: An Introduction to the New Keynesian Framework. Princeton University Press, Princeton, NJ.

Gavin, William T., Benjamin D. Keen, Alexander Richter, and Nathaniel Throckmorton, 2015. "The Zero Lower Bound, the Dual Mandate, and Unconventional Dynamics." Journal of Economic Dynamics and Control, 55, 14-38.

Gust, Christopher, Edward P. Herbst, David López-Salido, and Matthew E. Smith, 2017. "The Empirical Implications of the Interest-Rate Lower Bound." American Economic Review, forthcoming. 
Herbst, Edward P., and Frank Schorfheide, 2015. Bayesian Estimation of DSGE Models. Princeton University Press, Princeton, NJ.

Hills, Timothy S., Taisuke Nakata, and Sebastian Schmidt, 2016. "The Risky Steady State and the Interest Rate Lower Bound." Finance and Economics Discussion Series 2016-009, Board of Governors of the Federal Reserve System.

Hirose, Yasuo, and Atsushi Inoue, 2016. "The Zero Lower Bound and Parameter Bias in an Estimated DSGE Model." Journal of Applied Econometrics, 31(4), 630-651.

Hirose, Yasuo, and Takeki Sunakawa, 2015. "Parameter Bias in an Estimated DSGE Model: Does Nonlinearity Matter?" Centre for Applied Macroeconomic Analysis Working Paper 52/2014, Australian National University.

Holston, Kathryn, Thomas Laubach, and John C. Williams, 2016. "Measuring the Natural Rate of Interest: International Trends and Determinants," Working Paper Series 2016-11, Federal Reserve Bank of San Francisco.

Iiboshi, Hirokuni, Mototsugu Shintani, and Kozo Ueda, 2017. "Estimating the Nonlinear New Keynesian Model with the Zero Lower Bound for Japan," mimeo.

Johannsen, Benjamin K., and Elmar Mertens, 2016. "A Time Series Model of Interest Rates With the Effective Lower Bound." Finance and Economics Discussion Series 2016-033, Board of Governors of the Federal Reserve System.

Judd, Kenneth L., Lilia Maliar, Serguei Maliar, and Rafael Valero, 2015. "Smolyak Method for Solving Dynamic Economic Models: Lagrange Interpolation, Anisotropic Grid and Adaptive Domain." Journal of Economic Dynamics and Control, 44, 92-123.

Justiniano, Alejandro, and Giorgio E. Primiceri, 2010. "Measuring the Equilibrium Real Interest Rate." Economic Perspectives, 1Q/2010, 14-27.

Kiley, Michael T., 2015. "What Can the Data Tell Us About the Equilibrium Real Interest Rate?" Finance and Economics Discussion Series 2015-077, Board of Governors of the Federal Reserve System.

Laubach, Thomas, and John C. Williams. 2003. "Measuring the Natural Rate of Interest." Review of Economics and Statistics, 85(4), 1063-1070. 
Laubach, Thomas, and John C. Williams. 2016. "Measuring the Natural Rate of Interest Redux." Business Economics, 51(2), 57-67.

Lubik, Thomas A., and Christian Matthes. 2015. "Calculating the Natural Rate of Interest: A Comparison of Two Alternative Approaches." Federal Reserve Bank of Richmond Economic Brief, October 2015, EB15-10.

Lubik, Thomas A., and Frank Schorfheide, 2004. "Testing for Indeterminacy: An Application to U.S. Monetary Policy." American Economic Review, 94(1), 190-217.

Malin, Benjamin A., Dirk, Krueger, and Felix Kubler, 2011. "Solving the Multi-Country Real Business Cycle Model using a Smolyak-Collocation Method." Journal of Economic Dynamics and Control, 35(2), 229-239.

Nakata, Taisuke, 2016a. "Uncertainty at the Zero Lower Bound." American Economic Journal: Macroeconomics, forthcoming.

Nakata, Taisuke, 2016b. "Optimal Fiscal and Monetary Policy with Occasionally Binding Zero Bound Constraints." Journal of Economic Dynamics and Control, 73, 220-240.

Neiss, Katharine S., and Edward Nelson, 2003. "The Real-Interest-Rate Gap as an Inflation Indicator." Macroeconomic Dynamics, 7(2), 239-262.

Ngo, Phuong V., 2014. "Optimal Discretionary Monetary Policy in a Micro-Founded Model with a Zero Lower Bound on Nominal Interest Rate." Journal of Economic Dynamics and Control, 45, $44-65$.

Pescatori, Andrea, and Jarkko Turunen, 2015. "Lower for Longer: Neutral Rates in the United States." IMF Working Papers 2015/135, International Monetary Fund.

Richter, Alexander, and Nathaniel Throckmorton, 2016a. "Are Nonlinear Methods Necessary at the Zero Lower Bound?" Working Papers 1606, Federal Reserve Bank of Dallas.

Richter, Alexander, and Nathaniel Throckmorton, 2016b. "Is Rotemberg Pricing Justified by Macro Data?" Economics Letters, 149, 44-48.

Smets, Frank, and Rafael Wouters, 2007. "Shocks and Frictions in US Business Cycles: A Bayesian DSGE Approach." American Economic Review, 97(3), 586-606. 
Taylor, John B., 1993. "Discretion Versus Policy Rules in Practice." Carnegie-Rochester Conference Series on Public Policy, 39(1), 195-214.

Wicksell, Knut, 1898. Interest and Prices (English translation by R.F. Kahn, 1936). Macmillan, London.

Williams, John C. 2015. "The Decline in the Natural Rate of Interest." Business Economics, 50(2), $57-60$.

Woodford, Michael, 2003. Interest and Prices: Foundations of a Theory of Monetary Policy. Princeton University Press, Princeton, NJ. 
Table 1: Prior and posterior distributions of parameters

\begin{tabular}{lcccccc}
\hline \hline \multirow{2}{*}{ Parameter } & \multicolumn{3}{c}{ Prior } & & \multicolumn{2}{c}{ Posterior } \\
\cline { 2 - 3 } \cline { 7 - 8 }$\gamma$ & Distribution & Mean & S.D. & & Mode & S.D. \\
$\eta$ & Beta & 0.500 & 0.050 & & 0.684 & 0.032 \\
$\xi_{w}$ & Gamma & 2.000 & 0.250 & & 1.782 & 0.252 \\
$\iota_{w}$ & Beta & 0.500 & 0.050 & & 0.618 & 0.069 \\
$\xi_{p}$ & Beta & 0.500 & 0.050 & & 0.526 & 0.053 \\
$\iota_{p}$ & Beta & 0.500 & 0.050 & & 0.737 & 0.036 \\
$\phi_{\pi}$ & Beta & 0.500 & 0.050 & & 0.514 & 0.052 \\
$\phi_{y}$ & Gamma & 1.500 & 0.250 & & 2.075 & 0.201 \\
$\phi_{r}$ & Gamma & 0.125 & 0.050 & & 0.096 & 0.025 \\
$\bar{a}$ & Beta & 0.500 & 0.050 & & 0.784 & 0.020 \\
$\bar{\pi}$ & Normal & 0.540 & 0.100 & & 0.484 & 0.062 \\
$\bar{r}$ & Normal & 0.624 & 0.100 & & 0.634 & 0.049 \\
$\bar{l}$ & Gamma & 0.699 & 0.100 & & 0.675 & 0.057 \\
$\rho_{d}$ & Normal & 0.000 & 0.100 & & -0.011 & 0.095 \\
$\rho_{a}$ & Beta & 0.500 & 0.050 & & 0.691 & 0.034 \\
$\rho_{z}$ & Beta & 0.500 & 0.050 & & 0.402 & 0.041 \\
$100 \sigma_{d}$ & Beta & 0.500 & 0.050 & & 0.664 & 0.056 \\
$100 \sigma_{a}$ & Inv. Gamma & 0.500 & 2.000 & & 0.635 & 0.103 \\
$100 \sigma_{z}$ & Inv. Gamma & 0.500 & 2.000 & & 0.520 & 0.040 \\
$100 \sigma_{r}$ & Inv. Gamma & 0.500 & 2.000 & & 1.901 & 0.460 \\
\cline { 7 - 8 } & Inv. Gamma & 0.500 & 2.000 & & 0.145 & 0.012 \\
\hline
\end{tabular}


Figure 1: Data and smoothed estimates
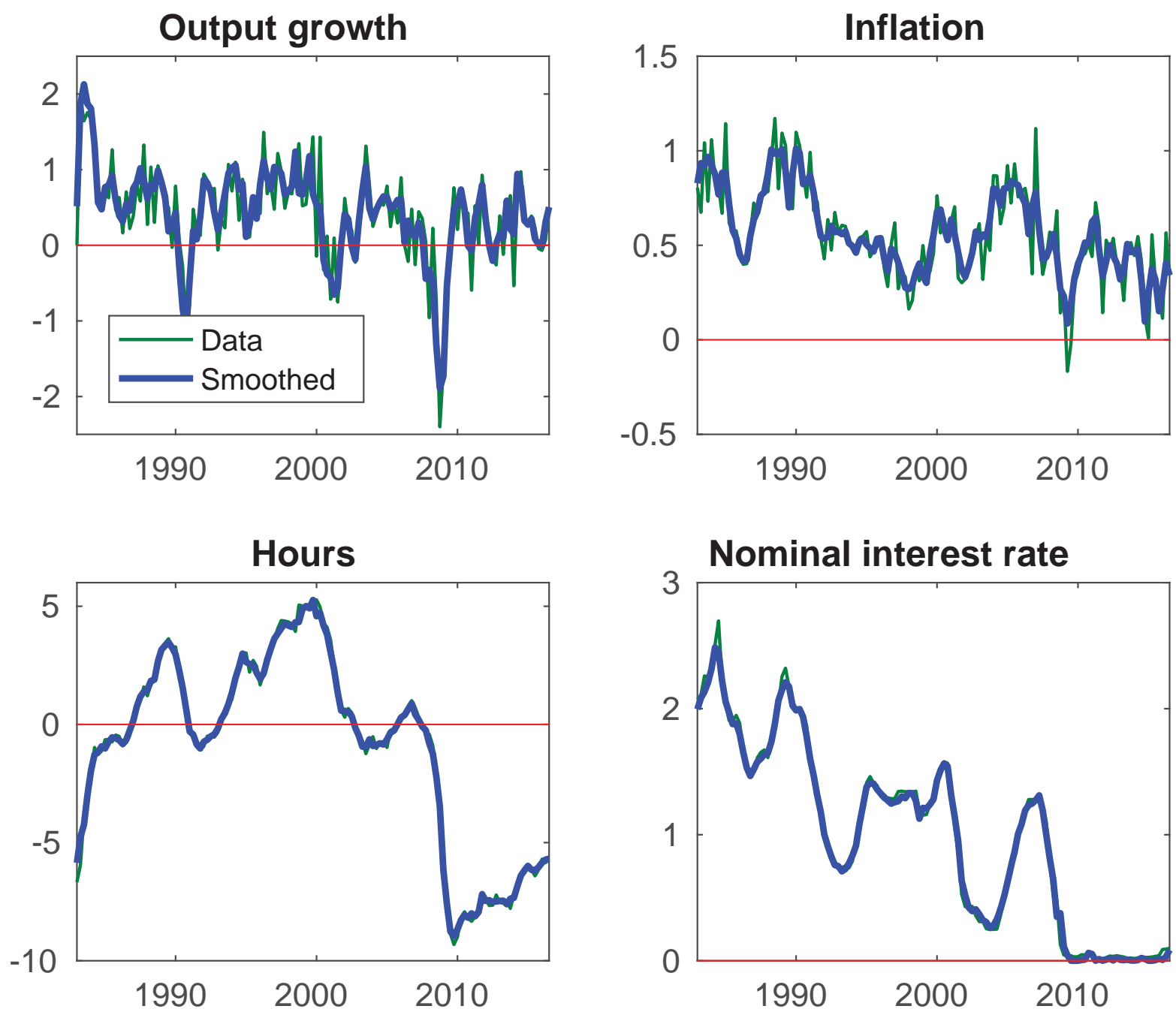

Note: The figure compares the data (thin lines) on output growth, inflation, hours worked, and the nominal interest rate with the smoothed mean estimates (thick lines) of the corresponding variables. 
Figure 2: Natural rate of interest

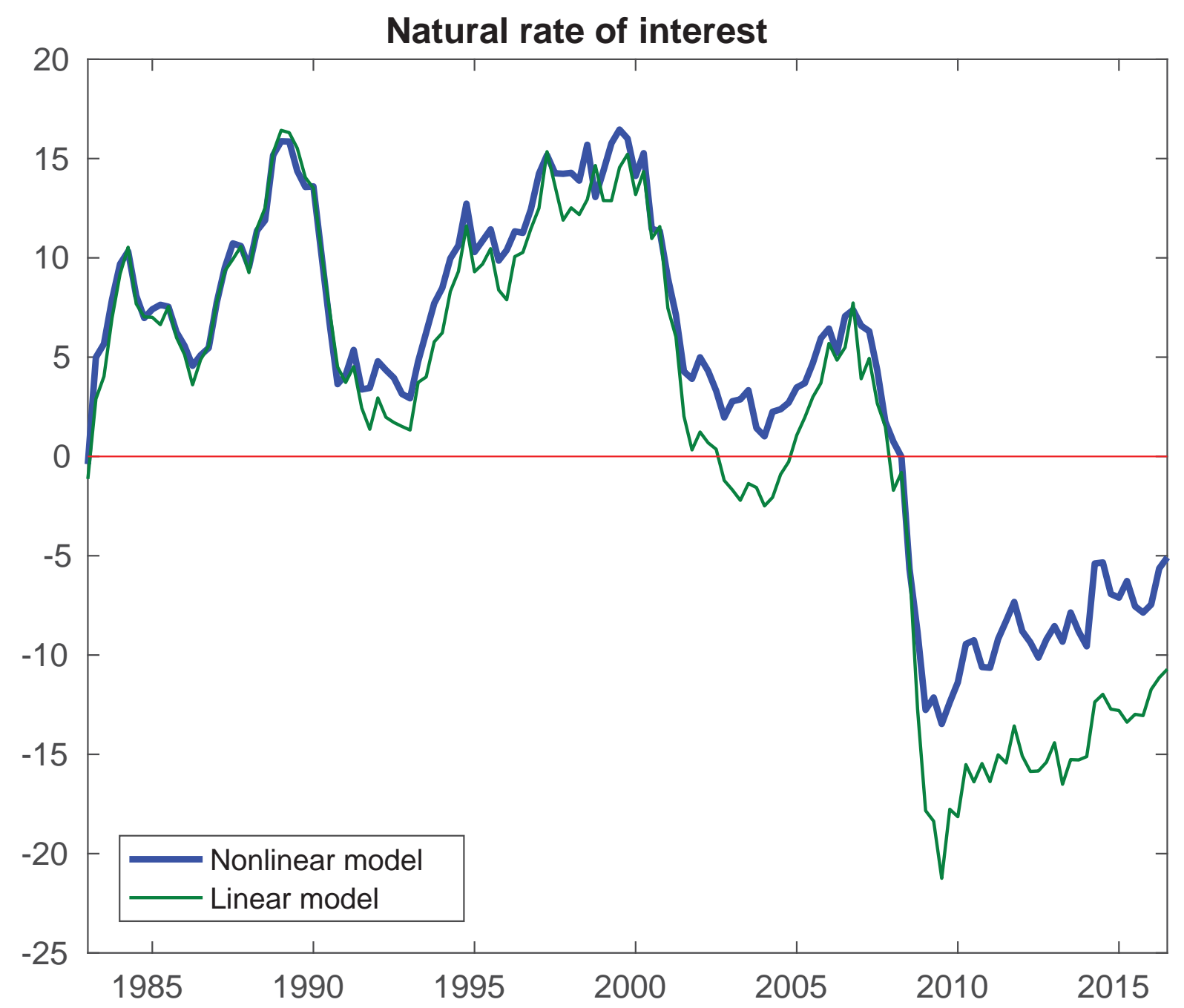

Note: The figure compares the smoothed mean estimate of the natural interest rate, in annualized terms, based on the nonlinear model (thick line) with that based on the linear model (thin line). 
Figure 3: Estimated shocks
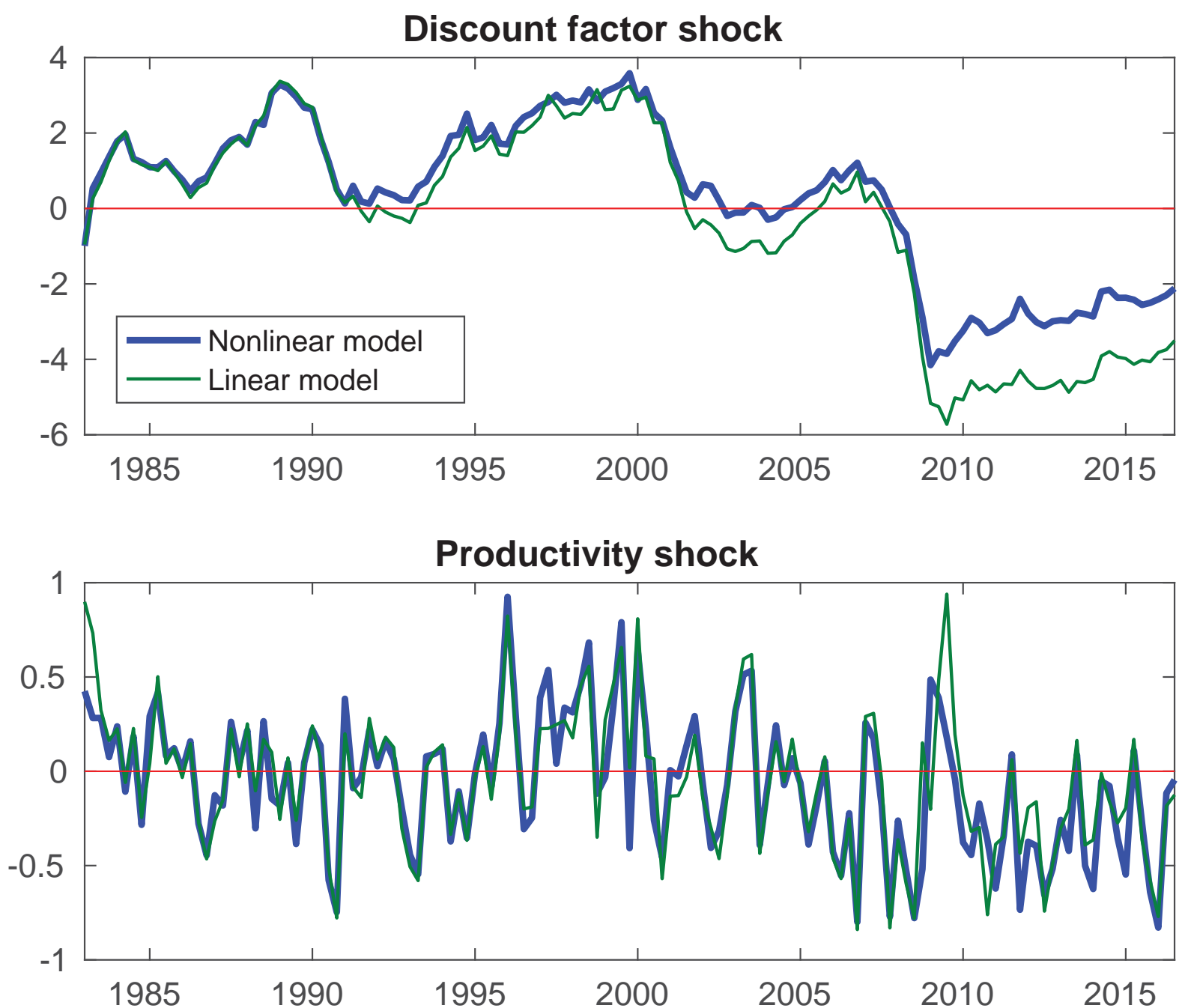

Note: The figure compares the smoothed mean estimates of the discount factor shocks $d_{t}$ and the productivity shocks $a_{t}$, in percentage terms, based on the nonlinear model (thick lines) with those based on the linear model (thin lines). 
Figure 4: Expected inflation and output

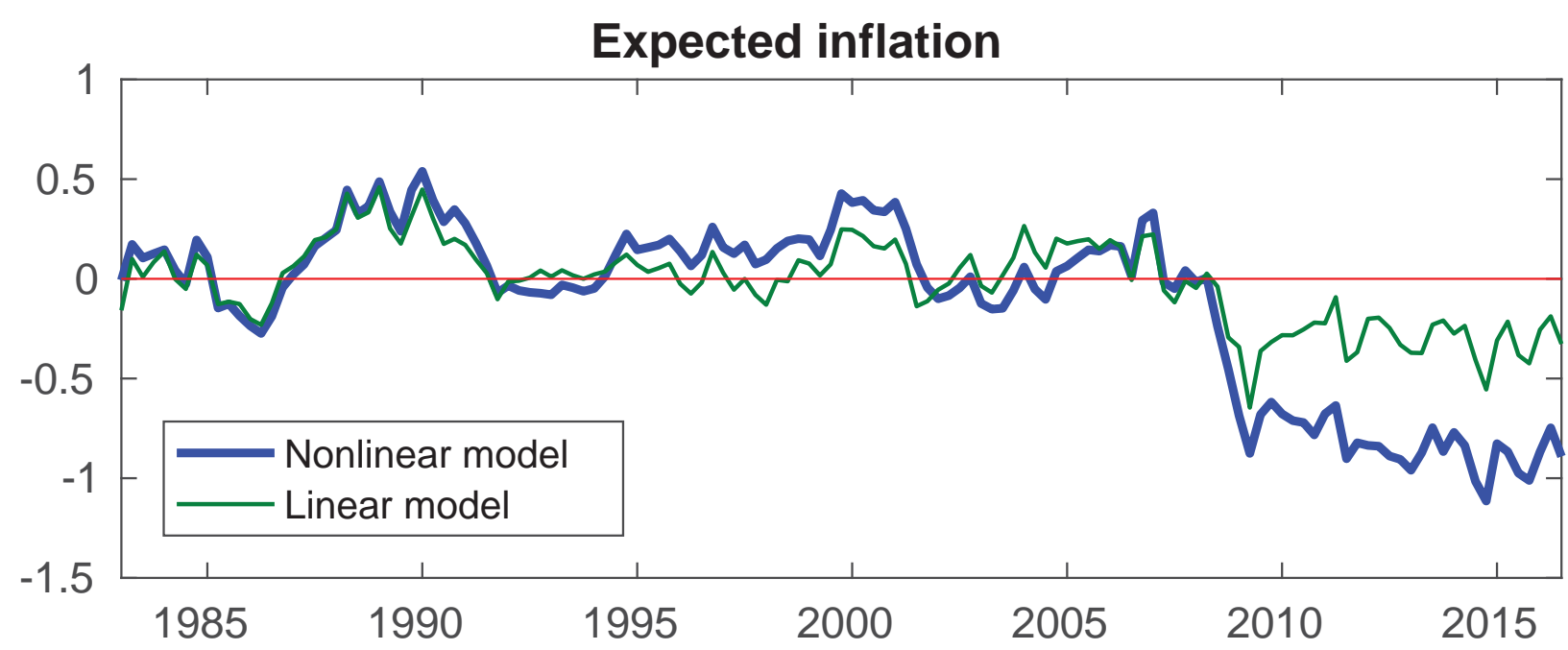

\section{Expected output}

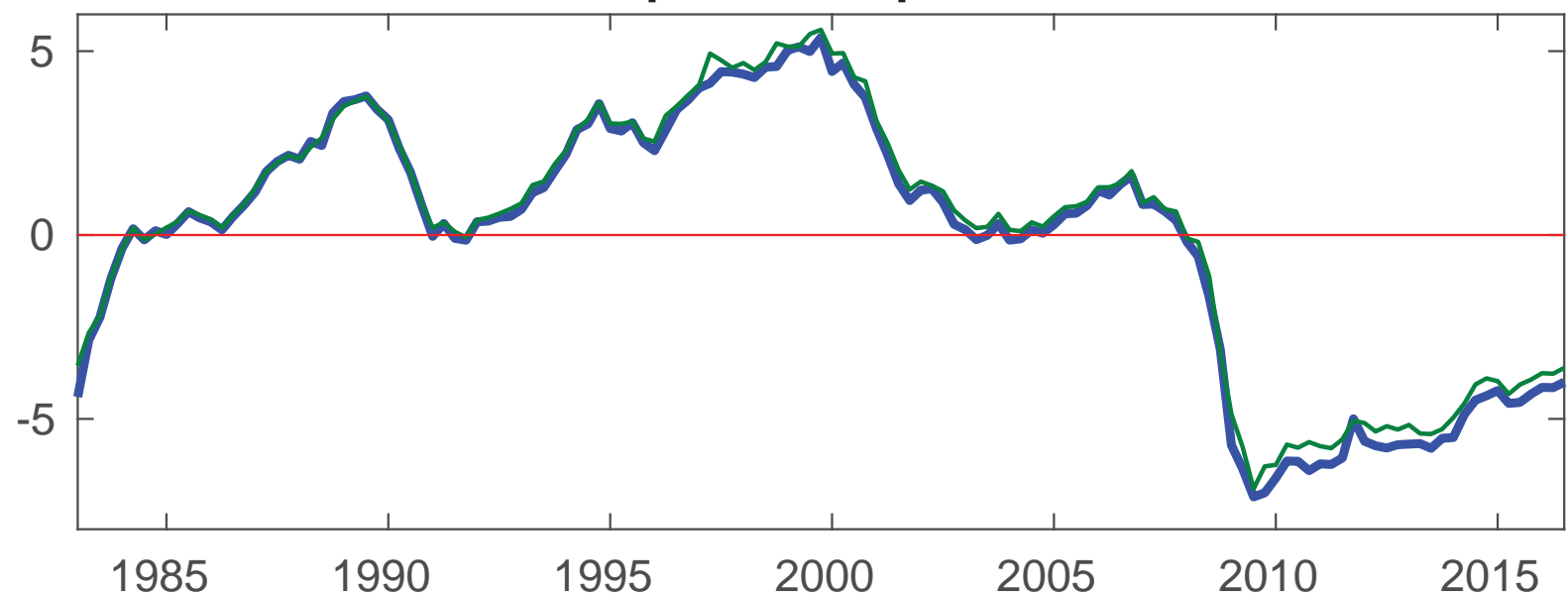

Note: The figure compares the smoothed mean estimates of expected inflation $E_{t} \log \Pi_{t+1}$ and expected output

$E_{t} y_{t+1}$, in terms of percentage deviation from the steady state, based on the nonlinear model (thick lines) with those based on the linear model (thin lines). 
Figure 5: Price and wage dispersion
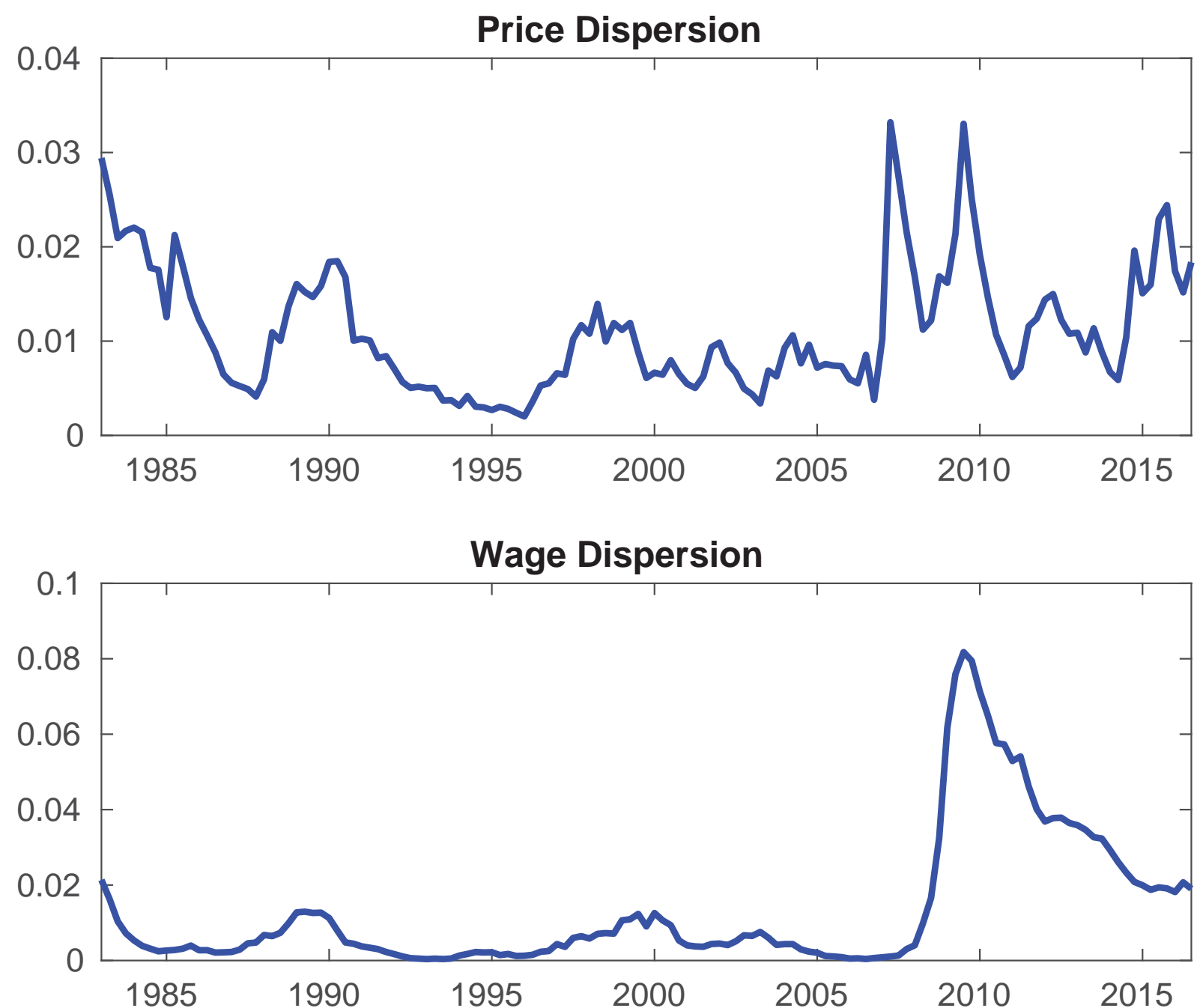

Note: The figure shows the smoothed mean estimates of the price and wage dispersion in terms of percentage deviation from the steady state. 
Figure 6: Natural rate of interest (Nonlinear vs. Quasi-linear)

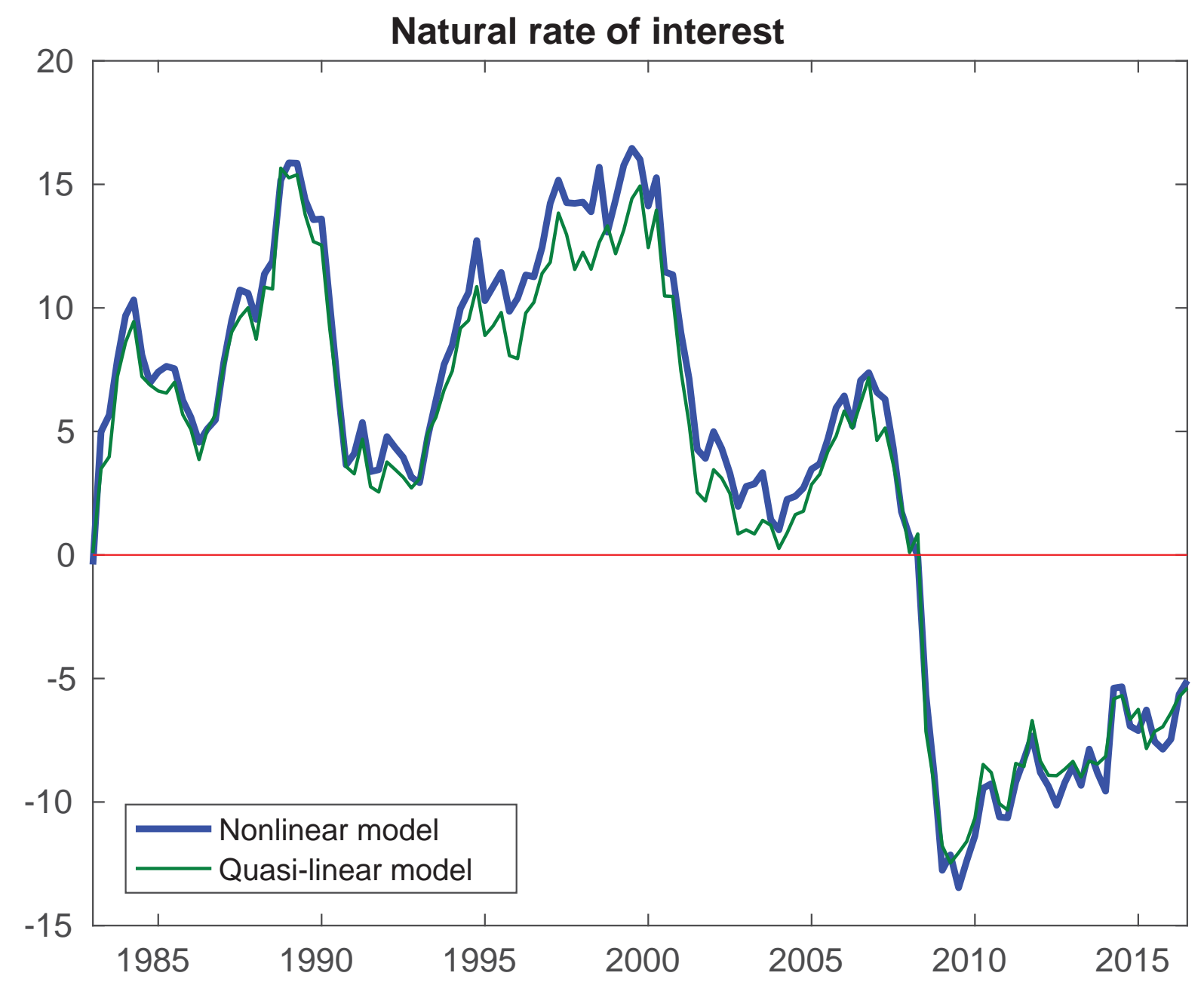

Note: The figure compares the smoothed mean estimate of the natural interest rate, in annualized terms, based on the nonlinear model (thick line) with that based on the quasi-linear model (thin line). 
Figure 7: Estimated shocks (Nonlinear vs. Quasi-linear)
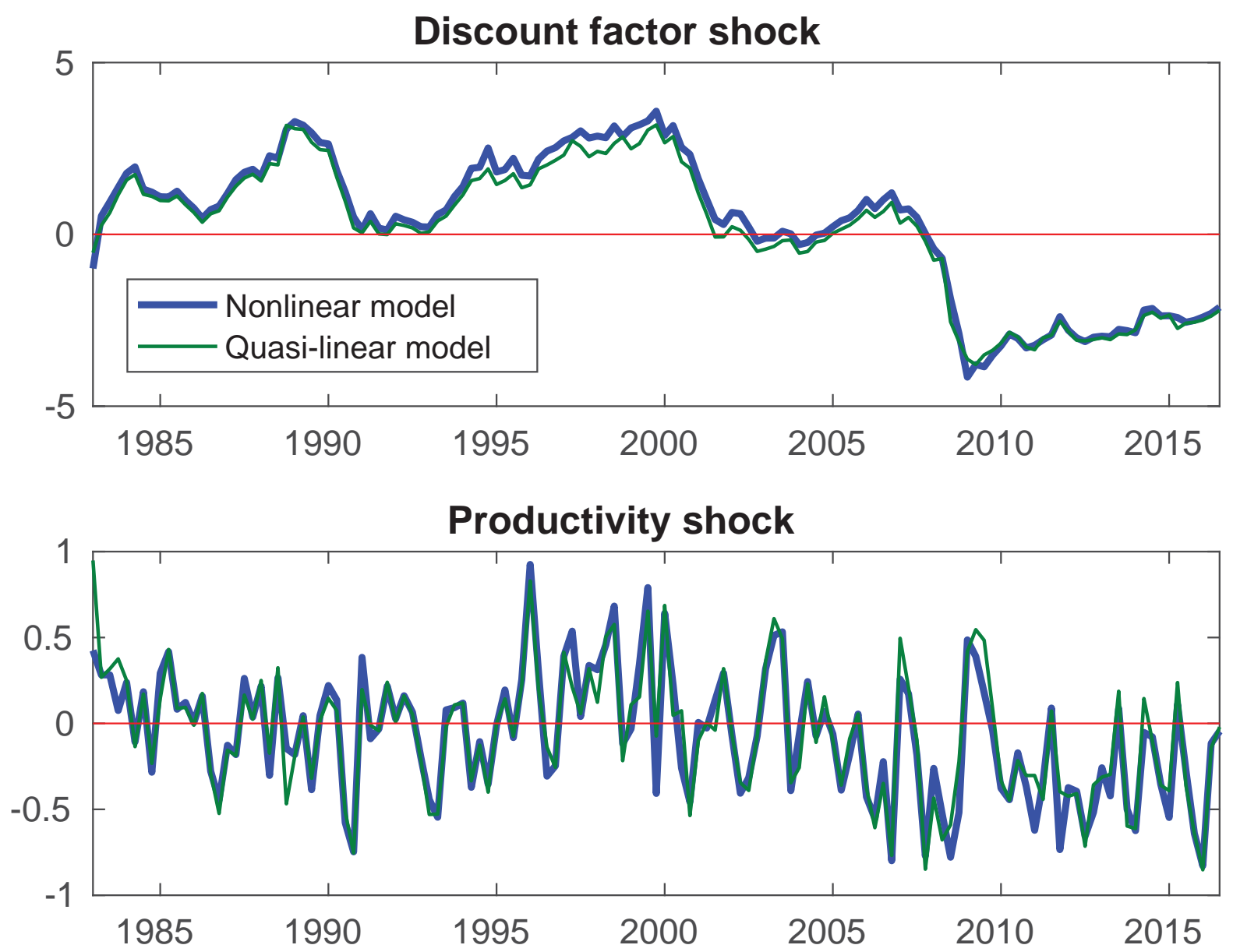

Note: The figure compares the smoothed mean estimates of the discount factor shocks $d_{t}$ and the productivity shocks $a_{t}$, in percentage terms, based on the nonlinear model (thick lines) with those based on the quasi-linear model (thin lines). 